\title{
ESTUDIO JURISPRUDENCIAL SOBRE EL RÉGIMEN JURÍDICO-PROCESAL DE LAS CLÁUSULAS DE JURISDICCIÓN INSERTAS EN CONOCIMIENTOS DE EMBARQUE: SITUACIÓN ACTUAL Y FUTURO PROYECTADO
}

\author{
JURISPRUDENCIAL EXAMINATION ON THE LEGAL \\ AND PROCEDURAL REGIME OF JURISDICTION CLAUSES \\ INSERTED IN BILLS OF LADING: CURRENT SITUATION \\ AND FORESEEABLE FUTURE
}

\author{
Francisco de Borja LangelaAn Osset \\ Contract Analyst within Contracts Department \\ Cepsa Trading S.A.U.
}

Recibido: 15.01 .2019 / Aceptado: 25.01 .2019
https://doi.org/10.20318/cdt.2019.4626

\begin{abstract}
Resumen: El presente trabajo se propone realizar un análisis jurisprudencial de la normativa procesal en la Unión Europea aplicable a las cláusulas de jurisdicción insertas en conocimientos de embarque. En este sentido, se estudian el art. 25 del Reglamento 1215/2012 y el art. 468 de la LENMAR, tratando los problemas procesales que ambos plantean. Por otro lado, se realiza un análisis a la luz de la jurisprudencia y doctrina anterior a la LENMAR para proyectar en el futuro la aplicabilidad real del mencionado art. 468. Este análisis se completa con una breve explicación inicial sobre el transporte de mercancías en régimen de conocimiento de embarque con el objeto de contextualizar la materia de estudio del presente trabajo.
\end{abstract}

Palabras clave: cláusulas de jurisdicción, conocimiento de embarque, Reglamento 1215/2012, Ley de Navegación Marítima, art. 468 LNM.

Abstract: The aim of this paper is to carry out a jurisprudential examination on the procedural Regulations applicable within the European Union to jurisdiction clauses inserted in Bills of Lading. Accordingly, art. 25 Regulation 1215/2012 and art. 468 LENMAR are studied, tackling the procedural problems that both articles raise. On another note, a scrutiny of the jurisprudence and doctrine previous to the LENMAR is carried out, so that the real enforceability of the above-mentioned art. 468 is projected into the future. This inquiry is completed by an introductory explanation about the international carriage of goods by sea, so as to contextualize the subject of this paper.

Keywords: jurisdiction clauses, Bill of Lading, UE Regulation 1215/2012, Spanish Maritime Act, art. 468 LNM.

Sumario: Sumario: I. Algunas consideraciones sobre el transporte marítimo internacional de mercancías. El conocimiento de embarque. 1. Consideraciones generales. 2. Régimen jurídico. 3. Concepto, caracteres y clases de conocimientos de embarque. 4. Contenido. 5. Funciones. 6. El conocimiento de embarque no es el contrato de transporte. II. Origen, evolución y situación actual de las normas que regulan la prórroga de jurisdicción en la Unión Europea. 1. La falta de normativa procesal específica en Derecho Marítimo. 2. La prórroga de la competencia con carácter general en 
la Unión Europea. 3. Régimen jurídico aplicable en la actualidad. El Reglamento 1215/2012 y el Convenio de Lugano de 2007. A) Ámbito material. B) Ámbito temporal. C) Ámbito territorial. 4. Límites a la autonomía jurisdiccional de las partes. A) Consideraciones generales sobre la autonomía jurisdiccional de las partes. B). Análisis del sistema competencial del Reglamento 1215/2012 en relación con el transporte marítimo internacional de mercancías. a) Competencias exclusivas. b) Supuestos especiales de protección. c) Sumisión tácita como criterio de atribución de competencia. d) Límite general a la autonomía jurisdiccional de las partes. III. Vinculación entre el tribunal designado y la relación jurídica litigiosa. IV. Aplicabilidad proyectada del art. 468 LENMAR. 1. Planteamiento general del problema. 2. Sobre la posible aplicabilidad del art. 468 LENMAR. 3. Sobre la posible inaplicabilidad del art. 468 LENMAR. A) Primacía del Derecho Internacional General y del Derecho de la Unión Europea. B) Interpretación alternativa de la STJCE Coreck en relación con la primacía del Derecho de la Unión Europea. C) Conclusiones del Encuentro de los Magistrados de lo Mercantil 2016 (especial mención al art. 468 LENMAR). V. Conclusiones.

\section{Algunas consideraciones sobre el transporte marítimo internacional de mercancías. El conoci- miento de embarque}

\section{Consideraciones generales}

1. En primer lugar y antes de entrar en el análisis de los artículos objeto de estudio, es necesario realizar algunas consideraciones sobre el transporte que genera las relaciones contractuales que producen, a su vez, la documentación del transporte en la que se insertan las cláusulas de jurisdicción, así como su diferenciación, siquiera someramente, con las figuras del fletamento ${ }^{1}$, del cabotaje y de otros documentos similares.

2. Debemos señalar que el contrato de transporte marítimo de mercancías se puede realizar de ordinario mediante la modalidad de fletamento de un buque (por tiempo o por viaje) por el que el porteador se obliga, a cambio de una contraprestación denominada flete, a transportar por mar mercancías y a entregarlas al destinatario en el puerto o lugar de destino (art. 203 LENMAR), asumiendo el fletador la gestión comercial del buque (art. 204.2 LENMAR).

3. Cuando el fletamento se refiera a mercancías determinadas por su peso, medida o clase, en un buque que permita una pluralidad de cargamentos, estaremos ante un contrato de mercancías en régimen de conocimiento o de fletamento para el transporte de mercancías determinadas en régimen de conocimiento de embarque (art. 205 LENMAR), en el que el fletador/cargador simplemente contrata el transporte.

4. Tanto el fletamento como el transporte de mercancías en régimen de conocimiento de embar$q^{2} e^{2}$ forman parte de los denominados por la LENMAR como contratos de utilización del buque. Dado que no es objeto de este trabajo analizar en profundidad las diferencias entre el contrato de fletamento (por tiempo o por viaje) y el contrato de transporte de mercancías en régimen de conocimiento de embarque, baste el siguiente cuadro para ilustrar brevemente sus diferencias fundamentales ${ }^{3}$ :

\footnotetext{
${ }^{1}$ Wolters Kluwer. "Contrato de fletamento". [Consultado el 04/01/2019]. Acceso en: http://guiasjuridicas.wolterskluwer. es/Content/Documento.aspx?params=H4sIAAAAAAAEAE1OMQ7CMAz8TZZKqO3GkKUUJoQQVIjVTUwbkcaQOKX9P YEyYMnyyXe6u2dEPzc4sVTk2ANTpjG7WWQY0DGJMDty8yAbH1EwtEHmAhRHsDUpWXywGbGBNv3Ja_TVnBATgz1hkGUpQk-vA4ymAzbkKvCL19Fabq_5Z4oyX-diRB-SQF5M15JR9Kbr92150QcEr_ojdCh3JiiwKwiPSVh3T0XOX_ JfWEXmZNayWzihbLo1MG7AotO_Gm9vVqA0AAEAAA==WKE.

2 Wolters Kluwer. "Contrato de transporte de mercancías en régimen de conocimiento". [Consultado el 04/01/2019]. Acceso en: http://guiasjuridicas.wolterskluwer.es/Content/Documento.aspx?params=H4sIAAAAAAAEAE1PwU7DMAz9GnKp hNqJAxxy6cZhEiA0CuLqplYbLbVH7I7173HXHYgUxe_52XnvZ8I8N3hRv2XSDMpFh4UVJCfOigsaMQegcDeVJXYgBV KRr-Cpj6MBkwQmDnGMSMpOZmKaR9_kCZ1CK750EHSCtOPgq6WOZ2ygNZ5zh7merVJWSAcU_7BxMvDvG5xjDx qZasjrrth1_vm7XE61qapHd8YsJvBfsbef0Q2xH17s6qoHkSjXXJz2NtoyH5vdduWb-YT-FRVWeADq0WwIQg7DOxgwt9O4JLoHOV1coqMxH9f-zY98kiURSP_ZdUM9qZqzVmntuZDs3YHiFhJSd8v0B4zvuxKAAQAAWKE.

${ }^{3}$ Para una visión general de los elementos personales, reales y formales del transporte en régimen de conocimiento, vid. Wolters Kluwer. "Derecho Marítimo". [Consultado el 04/01/2019]. Acceso en: http:/guiasjuridicas.
} 


\begin{tabular}{|c|c|c|}
\hline Requisitos esenciales & $\begin{array}{c}\text { Contrato de fletamento por tiempo } \\
\text { o por viaje }\end{array}$ & $\begin{array}{c}\text { Transporte en régimen de } \\
\text { conocimiento de embarque }\end{array}$ \\
\hline Consentimiento & \multicolumn{2}{|c|}{ Concurso oferta-aceptación sobre la cosa y la causa } \\
\hline Objeto & $\begin{array}{c}\text { Puesta a disposición de buque } \\
\text { determinado por contrato, armado y y } \\
\text { equipado }\end{array}$ & $\begin{array}{c}\text { Reserva de espacio de carga para } \\
\text { transporte de mercancías con inde- } \\
\text { pendencia del buque }\end{array}$ \\
\hline Causa & \multicolumn{2}{|c|}{ Transporte de mercancías } \\
\hline Documentación & $\begin{array}{c}\text { Póliza de fletamento y conocimiento } \\
\text { de embarque (art. 204.3. LENMAR) }\end{array}$ & $\begin{array}{c}\text { Conocimiento de embarque (art. } \\
\text { 246.1. LENMAR y art. 3.3 } 3^{\circ} \text { RLHV) }\end{array}$ \\
\hline
\end{tabular}

Fuente: elaboración propia a partir de la aplicación de los art. 1.262, 1.271 y 1.274 del Código Civil a ambos contratos de transporte.

5. Centrándonos en el contrato de transporte de mercancías en régimen de conocimiento y siguiendo la clasificación para el contrato de transporte mercantil ofrecida por PADILLA GonZÁLEZ / CLAVEro Ternero / Pendón Meléndez ${ }^{4}$, podemos clasificar el transporte de mercancías en régimen de conocimiento de embarque como un transporte marítimo internacional de mercancías operado por navieras en servicios de línea regular ${ }^{5}$, en el que el porteador asume la obligación de transportar las mercancías de un puerto a otro a cambio de un precio llamado flete. Este tipo de transporte tiene su origen en el crecimiento del comercio mundial (tanto de importaciones como de exportaciones), junto a la evolución de la técnica de la navegación y el aumento en la demanda de transportes. Esto hizo aparecer líneas regulares ${ }^{6}$ en las que en un buque indeterminado una pluralidad de cargadores ocupa su espacio de carga y lo que importa en el contrato no es tanto el buque en sí, como el transporte de la mercancía ${ }^{7}$.

6. Pero, ¿Qué ocurre cuando el transporte marítimo se realiza entre puertos de un mismo Estado por empresas de ese Estado? ¿Y si la naviera está domiciliada en otro Estado de la UE, pero opera entre puertos españoles? Ello determina que nos encontramos ante la figura del cabotaje y, por tanto, supone la aplicación del Reglamento (CEE) núm. 3577/92 del Consejo de 7 de diciembre de 1992 por el que se aplica el principio de libre prestación de servicios a los transportes marítimos dentro de los Estados miembros (cabotaje marítimo), al tratarse de "servicios de transporte marítimo dentro de un Estado miembro" que se prestarán "en las mismas condiciones que impone dicho Estado a sus propios nacionales". Además, aunque el Reglamento 1215/2012 no lo exija expresamente, se deduce de las disposiciones estudiadas que se requiere implícitamente un elemento de internacionalidad jurídicamente relevante.

7. Esto supone que, por ejemplo, en un transporte marítimo de mercancías en régimen de conocimiento de embarque entre el puerto de Barcelona y el puerto de Vigo, la cláusula de sumisión a un tribunal de Valencia no estará sujeta a dicho Reglamento, sino a la normativa procesal de Derecho español de origen interno, aunque la naviera sea extranjera ${ }^{8}$. También se consideran operaciones de cabotaje los

wolterskluwer.es/Content/Documento.aspx?params=H4sIAAAAAAAEAC1O0WrDMAz8mvplUJJ2Y-zBD83SQaEZowtjr4ojHDHX7mQ5a_5-7jyB0KE77u47IS89XkW3yGimcNcBr1JV4Sh0DiouPvjlrHtOqASGqCsFRhK4Nhhd3zDN2MOQ_4FH5GbJSIKAO2HU9fZBxSn8vMJMFoSCb4CLGY2j3n9Wt6k328cnNSPHLNAfZNELqonsdMwrRW85pMsLO UFuQUB3u35_OuxWm_sO2YAXcioisJnewKI-eDIU1hAvV-X8V277_kcWsyJskkgOHMQXThmXb3bHZ3Dox_-qv1BCVESkAQAAWKE.

${ }^{4}$ R. Padilla González / M. Clavero Ternero / A. M. Pendón Meléndez, “Lección 21. a Transportes”, en J. G. Jiménez Sánchez / A. Díaz Moreno (Coords.), Lecciones de Derecho Mercantil, Tecnos, Madrid, 2013, pp. 599 y 600.

${ }^{5}$ Entendemos por servicio de línea regular aquél sujeto a itinerarios, escalas frecuentes, así como tarifas y condiciones del transporte previamente establecidas por el porteador.

${ }^{6}$ A. Ruiz De Velasco, Manual de Derecho Mercantil, Universidad Pontificia Comillas, Madrid, 2008, p.1170.

${ }^{7}$ L. Fontestad Portalés, Conocimiento de embarque como título ejecutivo. Tirant Lo Blanch, Valencia, 1997, epígrafe II (versión electrónica)

${ }^{8}$ Nos referimos a la Ley 1/2000 de Enjuiciamiento Civil, por lo que respecta al ámbito procesal, y a la Ley 14/2014 de Navegación Marítima y al Reglamento (CEE) núm. 3577/92, por lo que respecta al ámbito material. 
desplazamientos desde o hacia la Península entre ésta y las Islas Canarias o las Islas Baleares, así como entre las islas de dichos archipiélagos, y los transportes desde o hacia Ceuta y Melilla desde las Islas o desde la Península.

\section{Régimen jurídico}

8. La pluralidad de normas internacionales y la intensa actividad legislativa del legislador español en los últimos cuatro años, hace necesario que nos planteemos las normas que resultan de aplicación al presente trabajo para así poder descartar aquello que no es aplicable y poder analizar mejor el conocimiento de embarque como documento del transporte marítimo.

9. Por lo que respecta al régimen jurídico de Derecho interno de este documento del transporte en nuestra legislación, hasta la entrada en vigor de la Ley 14/2014, de 24 de julio, de Navegación Marítima (en adelante LENMAR) ${ }^{9}$, cuya Disposición única derogatoria, apartados c) y d), derogó por completo el Libro III del Código de Comercio ${ }^{10}$, así como la Ley de 22 de diciembre de 1949, sobre unificación de reglas para los conocimientos de embarque en los buques mercantes ${ }^{11}$, el régimen jurídico del conocimiento de embarque se recogía en la Sección $1^{\text {a }}$ del Título III del Libro III de dicho Código, concretamente en los arts. 706 a 718, y 18 a 23 de la mencionada Ley de 1949. Tras dicha derogación, el conocimiento de embarque ha pasado a estar regulado por la Sección $5^{\text {a }}$ del Capítulo II del Título IV de la LENMAR, en sus arts. 246 a $266^{12}$.

10. Por lo que respecta a los convenios internacionales, debemos hablar de los Convenios realizados por las Naciones Unidas (en adelante la ONU). En este sentido, en España resulta de aplicación el Convenio de Bruselas de 25 de agosto de 1924 sobre unificación de ciertas reglas en materia de conocimiento de embarque (conocido como Reglas de La Haya, o de La Haya-Visby tras los Protocolos 23 de febrero de 1968 y de 21 de diciembre de 1969 modificativos de las mismas) (en adelante RLHV). Este Convenio fue publicado en la Gaceta el 31 de julio de 1930, más tarde España ratificaría los dos Protocolos modificativos ${ }^{13} \mathrm{y}$, además, el art. 277.2 LENMAR dispone que los contratos de transporte de mercancías en régimen de conocimiento de embarque, tanto nacionales como internacionales, se regirán por este Convenio y por los protocolos que lo modifican de los que España sea Estado parte.

11. Sin embargo, las RLHV no regulan de manera íntegra el contrato de transporte de mercancías en régimen de conocimiento de embarque (Broseta Pont / Martínez Sanz) ${ }^{14}$, sino que se centran en la responsabilidad del porteador. A pesar de esta situación y de que tampoco contienen reglas de competencia judicial internacional, sin duda para favorecer el mayor número de ratificaciones posibles, las RLHV contienen normas sobre el contenido del conocimiento de embarque que, como hemos visto en la LENMAR, resultan de aplicación en España.

12. Existen otros dos convenios de la ONU que debemos mencionar. En primer lugar, se intentaron sustituir las RLHV por el Convenio de las Naciones Unidas sobre el Transporte Marítimo de Mer-

\footnotetext{
${ }^{9}$ BOE núm. 180, de 25 de julio de 2014, pp. 59193 a 59311. Referencia: BOE-A-20147877.

${ }^{10} B O E$ núm. 289, de 16 de octubre de 1885. Referencia: BOE-A-1885-6627.

${ }^{11}$ BOE núm. 358, de 24 de diciembre de 1949. Referencia: BOE-A-1949-12565.

${ }^{12}$ Una breve referencia sobre el régimen jurídico actual del conocimiento de embarque, puede encontrarse en: WoLTERS KLuwER. "Conocimiento de embarque". [Consultado el 12/01/2019]. Acceso en: http://guiasjuridicas.wolterskluwer.es/Content/Documento.aspx?params=H4sIAAAAAAAEAC1PQU7EMAx8DblUQu2KC4dctssBaUFoKYirm1ptRGuX2F22v8dti GR1xp7EMz8LprXBm_qaSRMoFx0WBkhmToobmzAFoHC31CV2IAVSkXby2MfJiEkCE4c4RSR1JysxrZNv0oJOoRVfOgi6wHji4KsNxys20FqfU4fpuBpSVhgvKP7h4GTg31e4xh40Mh0h5b9i1_mnr3I71aGsKnfFJCbwn7G3zeiG2A9nK816EImy5Lx2Z62zN_Nqc79Zp3Rv6BCphegHs2GIKQwvIERc7tMW6J7kPnmonyQ-RYY33dN3pH1x0XVfLRKeebCaPcJFGsYkbr_ BH_KgeajbgEAAA $==$ WKE.

${ }^{13}$ BOE núm. 36, de 11 de febrero de 1984, pp. 3674 a 3677.

14 M. Broseta Pont / F. Martínez Sanz, Manual de Derecho Mercantil. Volumen II. Contratos mercantiles. Derecho de los títulos-valores. Derecho Concursal. Tecnos, Madrid, 2014, p. 196.
} 
cancías (conocido como las Reglas de Hamburgo, en adelante RH). Este Convenio contiene disposiciones sobre competencia judicial internacional (art. $21 \mathrm{RH}$ ), pero no han sido ratificadas por España, por la UE ${ }^{15}$ ni por países de peso económico y político como, por ejemplo, los Estados Unidos de América.

13. Por último, en 2008 vio la luz el Convenio de las Naciones Unidas sobre el Contrato de Transporte Internacional de Mercancías Total o Parcialmente Marítimo (conocido como las Reglas de Rotterdam, en adelante RR). Este Convenio está, o estaba, llamado a sustituir tanto a las RLHV como a las RH, en un esfuerzo por unificar, modernizar y desarrollar los derechos y obligaciones de los cargadores, porteadores y destinatarios sujetos a un contrato de transporte de puerta a puerta que comprenda un tramo internacional por vía marítima. Aunque dichas Reglas también contienen disposiciones sobre competencia judicial internacional (arts. 66 a 69 RR), han sido ratificadas hasta el momento presente ${ }^{16}$ por cuatro países, siendo España el primero en hacerlo el 19 de enero de 2011 y, por otro lado, Togo en 2012, el Congo en $2014^{17}$ y Camerún en 2017, por lo que no parece que vayan a entrar en vigor en un futuro cercano, a pesar de la visión positiva que de esta circunstancia tiene un sector muy autorizado de nuestra doctrina mercantil ${ }^{18}$. Además, dichos artículos sobre reglas de jurisdicción internacional constituyen una materia denominada por el Derecho Internacional como "opt-in", según la cual sólo los Estados que manifiesten mediante declaración expresa estar vinculados por dichas normas de jurisdicción, lo estarán efectivamente, por lo que se permite (en sentido negativo) que no lo estén ${ }^{19}$.

\section{Concepto, caracteres y clases de conocimientos de embarque}

14. El conocimiento de embarque (en inglés Bill of Lading y Connaissement en francés) es uno de los principales documentos del transporte marítimo de mercancías en el cual se formaliza el contrato de transporte marítimo internacional de mercancías, es decir, la conclusión del contrato de transporte va acompañada de la emisión de una serie de documentos, en nuestro caso, del conocimiento de embar$q^{2}{ }^{20}$. Se trata de un título-valor, de tradición y ejecutivo emitido por el porteador, el capitán o el agente del porteador, que será entregado al cargador una vez que las mercancías estén cargadas en el buque (art. 3. 3. ${ }^{\circ}$ RLHV y art. 246.1 LENMAR) y que será firmado por el porteador o por su agente, presumiéndose que, si lo firma el capitán, lo hace por cuenta del porteador mencionado en el conocimiento (art. 249.1 LENMAR). En cuanto al momento de la emisión o entrega, éste tendrá lugar antes de iniciar al viaje.

15. La afirmación de que el conocimiento de embarque se trata de un título-valor implica una serie de consecuencias importantes derivadas precisamente de dicha calificación y, por ello, vamos a estudiar el conocimiento de embarque como título-valor utilizando una clasificación general para estos títulos ofrecida por JiMÉNEZ SÁNCHEZ / BAENA BAENA ${ }^{21}$. De esta forma, se trataría de un título-valor causal, pues las obligaciones asumidas en virtud del conocimiento de embarque tienen su causa en un contrato de transporte marítimo de mercancías previo a su emisión. Se trata de títulos literales completos, pues en ellos se recogen todos los derechos y obligaciones de las partes que derivan del contrato de transporte marítimo, así como las condiciones generales en las que se desarrolla dicho transporte, lo que incluye las cláusulas de jurisdicción. En este sentido, podemos citar como ejemplo un extracto del modelo de conocimiento de embarque emitido por la naviera Mediterranean Shipping Company (en adelante MSC)22:

${ }_{15} \mathrm{Vid}$. http://www.uncitral.org/uncitral/es/uncitral_texts/transport_goods/Hamburg_status.html.

16 Fecha de consulta: 04/01/2019.

${ }^{17}$ Aunque las RR parecen estar llamadas a suceder tanto a las RLHV como a las RH, no parece, dada su situación actual, que dicha sustitución se vaya a producir en un momento cercano al presente. Para conocer la situación actual de las Reglas de Rotterdam vid. http://www.uncitral.org/uncitral/es/uncitral_texts/transport_goods/rotterdam_status.html.

18 M. Broseta Pont / F. Martínez Sanz, Manual..., cit., p. 197.

$19 \mathrm{Vid}$. arts.74 y $91 \mathrm{RR}$.

20 S. Zunarelli / M. M. Comenale Pinto, Manuale di Diritto della Navigazione e dei Trasporti I, CEDAM, Lavis, 2013, p. 478.

${ }^{21}$ J. G. Jiménez SÁnchez / P. J. BAena BAena, "Lección 15. a La representación de las posiciones jurídicas en el tráfico mercantil. Los títulos-valores. Las anotaciones en cuenta”, en J. G. Jiménez SÁnchez / A. Díaz Moreno (Coords.), Lecciones..., cit., pp. 401 a 405.

${ }_{22}$ Msc. "MSC-CONOCIMIENTO DE EMBARQUE". 2017. [Consultado el 12/01/2019]. Acceso en: https://www.msc. 
"Al aceptar este C/E, el comerciante acepta expresamente, como si estuvieran rubricados, todos los términos y condiciones (estén impresos, en sellos o añadidos por cualquier otro medio a cualquiera de las caras de este documento) de este C/E. Asimismo, también acepta las condiciones de la tarifa del transportista".

16. Además, el conocimiento de embarque es, por su objeto, un título jurídico-real o de tradición, pues atribuye a su titular, como veremos en las funciones de este documento, una facultad de disposición sobre las mercancías que representa. En cuanto al sujeto emisor del conocimiento, se trata generalmente de un sujeto de Derecho Privado, al tratarse de empresas navieras de capital privado que se dedican a la explotación de los buques, sean propietarias o no de los mismos (art. 145.2 LENMAR). Por la manera de emitirse podemos decir que el conocimiento de embarque es un título-valor emitido en masa y utilizado de forma general y habitual por las navieras en sus transportes marítimos. Finalmente, por su forma de designar al titular, el conocimiento de embarque puede ser emitido al portador (cuando no mencione el nombre el destinatario), a la orden (del cargador o de la persona que éste designe) o nominativo (cuando en el conocimiento se exprese que la mercancía será entregada al mismo cargador o a una persona distinta de éste) (art. 250.1 LENMAR) y su ley de circulación será la simple entrega, el endoso y la cesión según las normas de la cesión de créditos no endosables respectivamente (art. 250.2 LENMAR).

17. Finalmente, el conocimiento de embarque es un título ejecutivo, es decir, tendrá aparejada ejecución de la obligación de entrega de las mercancías entregadas al porteador para su transporte. Así lo prescribe el art. 253 LENMAR y la jurisprudencia de nuestro Alto Tribunal (SSTS núm. 1040/1993, de 10 de noviembre, FJ. 6; y núm. 528/2004, de 15 de junio, FJ. 2).

\section{Contenido}

18. El contenido del conocimiento de embarque viene regulado por el art. 3. $3 .^{\circ}$ RLHV y por el art. 248.1 LENMAR. Estos artículos hacen referencia a una serie de menciones obligatorias, o contenido mínimo, que en el momento de entrega del conocimiento deberán recogerse en el mismo. Estas menciones obligatorias se refieren fundamentalmente a la identificación del porteador, del cargador y del destinatario (si el conocimiento es nominativo); identificación y descripción de las mercancías entregadas por el cargador con expresión de la naturaleza de las mismas, marcas de identificación, número de bultos, etc.; puertos de partida y destino (o de carga y descarga según la nomenclatura de la LENMAR), fecha de entrega de las mercancías al porteador y, si se hubiere pactado, la fecha o plazo de entrega en el lugar que corresponda. Además, se indicará el lugar de emisión del conocimiento y, si se hubiere emitido más de uno, se indicará el número de ejemplares originales.

19. Además de las menciones obligatorias descritas, el conocimiento podrá contener todas aquellas menciones voluntarias que las partes deseen incluir, es decir, aquellas estipulaciones válidamente pactadas por el cargador y el porteador (arts. 1.255 CC y 248.2 LENMAR). Es en este último numeral donde debemos ubicar las cláusulas de sumisión a la jurisdicción del tribunal o los tribunales de un Estado miembro de la UE.

\section{Funciones}

20. Como hemos visto, el conocimiento de embarque es un título-valor y no una carta de porte marítimo (análoga al Sea waybill) ${ }^{23}$. De esto se deduce que, cuando el documento es un "verdadero conocimiento de embarque" (STS núm. 528/2004, de 15 de junio, FJ. 2), aquél "despliega las funciones

com/getattachment/26461fb8-6e46-44a3-a71d-4b74dc8aafac/635581436758730000.

${ }^{23}$ La diferencia fundamental entre el Sea waybill y el conocimiento de embarque es que mientras que el primero se emite cuando no se prevé la transmisión de las mercancías, porque no están destinadas a su circulación (STS núm. 157/1997, de 3 de marzo, FJ. 1), el segundo se emite en el caso contrario, es decir, cuando las mercancías han de cambiar de poseedor y están llamadas a circular o se prevea su circulación (SAP de las Palmas núm. 241/2006, de 15 de mayo, FJ. 4). 
que les son propias" (SAP de Las Palmas núm. 253/1998, de 17 de junio, FJ. 3) y que son fundamentalmente tres: función contractual, función probatoria y función representativa (SAP de Barcelona núm. 241/2006, de 15 de mayo, FJ. 4).

21. Siguiendo a la Audiencia Provincial de Barcelona y a la Audiencia Provincial de las Palmas, podemos sintetizar las funciones que vienen reconocidas a los conocimientos de embarque en las siguientes: a) constituye el documento del contrato al que se incorporan las condiciones del transporte, es decir, es título contractual; b) constituye la prueba de que las mercancías han sido entregadas al porteador y cargadas a bordo del buque, es título probatorio (art. 256.1 LENMAR); y c) es un título representativo de las mercancías que incorpora el derecho del poseedor a reclamar al porteador las mercancías especificadas en el conocimiento (art. 252.1 LENMAR) y a disponer de ellas durante el viaje (art. 250.2 LENMAR), por tanto, es un título de crédito y de tradición. Estas funciones también han sido reconocidas por el Tribunal Supremo (STS núm. 1148/2002, de 29 de noviembre, FJ. 2).

\section{El conocimiento de embarque no es el contrato de transporte}

22. De las tres funciones del conocimiento, en este estudio nos interesa su función contractual. $\mathrm{Al}$ analizar las funciones del conocimiento de embarque mencionábamos en primer lugar que el conocimiento "constituye el documento del contrato, al que se incorporan las condiciones del transporte, con caracteres propios de los contratos de adhesión (título contractual)" (SAP de Barcelona núm. 241/2006, de 15 de mayo, FJ. 4) o, dicho en otras palabras, el conocimiento de embarque no es el contrato de transporte, sino que es la prueba del mismo (STS núm. 528/2004, de 15 de junio, FJ. 2.2; y SAP de las Palmas núm. 253/1998, de 17 de junio, FJ. 3) y es que dicho contrato suele preceder a la emisión del conocimiento de embarque (STS núm. 1148/2002, de 29 de noviembre, FJ. 2).

23. De lo anterior deducimos la primera característica del contrato de mercancías en régimen de conocimiento de embarque, a saber, que se trata de un contrato de carácter consensual, es decir, aquél para cuyo perfeccionamiento basta:

"[...] la voluntad, consciente y libremente emitida, [que] es aceptada por la persona a quien se dirige dicha declaración". En ese momento "se produce la perfección del contrato, el nacimiento de éste a la vida jurídica, cual proclama el artículo 1254 del Código Civil, del que, y de los artículos 1258 y 1262, se evidencia que dicha perfección surge de la simple concurrencia del consentimiento, de la coincidencia de las dos declaraciones de voluntad, recíprocas y sucesivas, que genera el acto jurídico bilateral"24.

24. En el caso del contrato en régimen de conocimiento, la oferta consistirá en el ofrecimiento de la naviera -normalmente a través de su página web- del espacio de carga, ruta, tipo de contenedor, etc., y la aceptación del cargador consistirá precisamente en reservar el espacio de carga, momento en el que comienza el contrato ${ }^{25}$, es decir, cuando exista acuerdo de voluntades sobre la realización del transporte ${ }^{26}$.

25. Podría pensarse que este tipo de contrato de transporte es un contrato real, que requiere para su perfección de la entrega de las mercancías, y formal, en el que no basta el consentimiento, sino que se exige para su perfeccionamiento la emisión y entrega del conocimiento de embarque. En primer lugar, la entrega de las mercancías, que es la obligación esencial del contrato, forma parte de la fase ejecutiva del mismo, es un presupuesto de dicha ejecución ${ }^{27}$ y es una obligación de resultado que ha asumido el

\footnotetext{
${ }^{24}$ Wolters KLUwer. "Perfección del contrato". [Consultado el 12/01/2019]. Acceso en: http://guiasjuridicas. wolterskluwer.es/Content/Documento.aspx?params=H4sIAAAAAAAEAMtMSbF1jTAAAUNTQ0tLtbLUouLM_ DzbsMz01LySVACTTaswIAAAAA= $=$ WKE.

${ }^{25}$ Centro De Comercio Internacional. "Conocimiento de embarque y manifiesto de carga". [Consultado el 12/01/2019]. Acceso en: http://www.intracen.org/guia-del-cafe/logistica-y-seguros/Conocimientos-de-embarque-y-manifiestode-carga/.

${ }^{26}$ F. SÁnchez Calero, El contrato de transporte marítimo de mercancías, Aranzadi, Pamplona, 2010 (versión electrónica).

${ }^{27}$ F. SÁnchez Calero, El contrato..., cit., (versión electrónica); y L. Fontestad Portalés, Conocimiento..., cit., (versión electrónica).
} 
porteador al ser el contrato de transporte una especie de subarrendamiento de obra. En segundo lugar, tampoco se puede afirmar que el contrato de transporte en régimen de conocimiento sea un contrato de carácter formal ya que, aunque es un documento que prueba la existencia del contrato, no constituye un presupuesto esencial para que exista ${ }^{28}$.

26. Otra prueba de que el contrato de transporte de mercancías en régimen de conocimiento de embarque es consensual es que antes de la emisión del conocimiento, es decir, antes del inicio del viaje, ya genera obligaciones para las partes, aunque sobre todo para el porteador. En primer lugar, el porteador debe cuidar la navegabilidad del buque en el sentido de que se debe encontrar en el estado adecuado para recibir el cargamento a bordo y transportarlo con seguridad a destino, teniendo en cuenta las circunstancias previsibles del viaje, sus fases y el tipo de cargamento (art. 212.1 LENMAR), de acuerdo con la diligencia de un ordenado porteador dedicado al transporte marítimo de mercancías (arts. 3. 1. ${ }^{\circ} \mathrm{RLHV}$, 212.3 LENMAR y 1.104 CC). Además, deberá el porteador poner a disposición del cargador el buque en el puerto y fecha convenidos por contrato (arts. 211 y 215 LENMAR) para que se puedan efectuar las operaciones de carga y estiba de las mercancías que, salvo pacto en contra, serán a su costa y riesgo (art. 218.2 LENMAR). Por tanto, la emisión del conocimiento de embarque no es un presupuesto para el nacimiento del contrato, sino para la aplicación de las RLHV (art. 1.b) RLHV). Por lo que respecta al cargador, éste deberá entregar las mercancías al porteador en un plazo que permita su embarque durante la estancia del buque en el puerto (art. 229 LENMAR). Es, por tanto, un contrato bilateral o sinalagmático perfecto, que genera obligaciones para ambas partes antes de la emisión del conocimiento, ya que dicha emisión está condicionada a la entrega de las mercancías por el cargador ${ }^{29}$.

27. Pero, sin duda, la característica más importante de este contrato de transporte, por lo que respecta a las cláusulas de prórroga de jurisdicción, es aquella según la cual el contrato de transporte en régimen de conocimiento de embarque es un contrato de adhesión (SSAP de Barcelona núm. 241/2006, de 15 de mayo, FJ. 4; y de Cantabria, Rec.704/1998, de 9 de diciembre, FJ. 5). Podemos afirmar que el contrato objeto de estudio se trata de un verdadero contrato de adhesión, o contrato-tipo ${ }^{30}$, toda vez que las condiciones del transporte han sido preestablecidas e impuestas por la empresa naviera, sin que se admitan modificaciones ni contraofertas, existiendo sólo una aceptación (o adhesión) pura y simple de las mismas por la otra parte, en nuestro caso el cargador.

28. Se mantiene en todo contrato de adhesión, y en este tipo también, la libertad para contratar (STS núm. 1084/1998, de 13 de noviembre, FJ. 2), pero no se mantiene la libertad de contratación o, dicho de otra manera, se mantiene la facultad de aceptar o no los términos y condiciones en que la naviera oferta realizar el transporte, pero no se dan en estos contratos "ni negociaciones ni ese tira y afloja de ofertas y contraofertas porque simplemente, [la naviera] ofrece celebrar un contrato [de transporte]

${ }^{28}$ G. Bercovitz Álvarez / A. Emparanza Sobejano / M. Iribarren Blanco / Ma . V. Petit Lavall / L. M. Piñoleta Alonso / I. Quintana CARLo, "Contratación del transporte y la navegación”, en R. Bercovitz RodríGuez-CAno / N. I. Moralejo Imbernón / M. S. Quicios Molina (Coords.), Tratado de contratos. Tomo 5. (Contratos del mercado de valores, contratación bancaria, contratación de transporte y navegación, contratos de seguro), Tirant lo Blanch, Valencia, 2013 (versión electrónica). En la SAP de Barcelona núm. 175/2013, de 29 de abril, FFJJ. 6 a 9, esta cuestión se pone de manifiesto con una claridad absoluta. La Audiencia declaró que, aunque no se había llegado a emitir el conocimiento de embarque el contrato de transporte marítimo existía, pues la consignataria, en ese caso, había asumido efectivamente la obligación de transportar. La Audiencia llega a esta conclusión analizando los correos electrónicos entre las partes, que revelan claramente la asunción de tal obligación. Por otro lado, y aunque no se mencione expresamente, consideramos que a esta misma conclusión se podría haber llegado aplicando los arts. 1.254 y 1.262 del Código Civil.

${ }^{29}$ En estas páginas estamos comentando la regla general, pero pudiera darse el caso de otras formas de conocimiento, como el conocimiento "recibido para embarque" (el cargador entrega la mercancía en los almacenes del naviero), las órdenes de entrega o delivery orders (presuponen la existencia de un conocimiento de embarque y permiten que su poseedor disponga durante el viaje de una parte de las mercancías cargadas) y el conocimiento directo o through bill of lading (cuando el transporte es asumido por varios porteadores y cada uno de los cuales realiza una parte del trayecto).

${ }^{30} \mathrm{~J}$. Ma . SÁNCHEZ MiRANDA, "La sumisión en los conocimientos de embarque y los procesos de limitación de la responsabilidad del armador en detrimento de los pequeños usuarios del transporte marítimo". 2017. [Consultado el 04/01/2019]. Acceso en: https://slidedoc.es/por-jose-maria-sanchez-miranda-amya-abogados-pdf. 
en determinadas condiciones inalterables". Esta oferta se realiza "al público en general" y para "quien quiera aceptarlas; pero sin [...] discusión sobre ellas, [...], negociaciones ni contraofertas", pudiendo concluir que el contrato de transporte en régimen de conocimiento "se acoge tal cual es, o se deja, y no hay contrato" ${ }^{31}$, como señala ALBALADEJO ${ }^{32}$ sobre los contratos de adhesión en general.

29. Por todo ello, nos encontramos ante condiciones generales de la contratación tipificadas en el tráfico marítimo internacional que reducen al mínimo la autonomía de la voluntad de quien celebra el contrato con el porteador, sin perjuicio de que se mantenga la libertad de contratar ${ }^{33}$.

\section{Origen, evolución y situación actual de las normas que regulan la prórroga de jurisdicción en la Unión Europea}

\section{La falta de normativa procesal específica en Derecho Marítimo}

30. Una vez hemos definido el transporte en el que se generan las cláusulas objeto de estudio, la siguiente cuestión pasa por la ausencia de un Derecho Procesal Marítimo, que no es cuestión menor, pues en Derecho Marítimo la jurisdicción internacional es un elemento esencial de las relaciones jurídicas que surgen con ocasión de la navegación marítima. Como señalan GABALdón García / Ruíz SOROA, el planteamiento de cuestiones prácticas en el ámbito del Derecho Marítimo comienza por el planteamiento de la jurisdicción competente. Esta cuestión no es nada desdeñable en esta rama del Derecho, sino que constituye un prius obligado para la solución material del fondo del litigio. No es, por tanto, una mera cuestión accesoria ${ }^{34}$.

31. El primer problema al que nos debemos enfrentar cuando analizamos la competencia judicial internacional en Derecho Marítimo es la falta de normativa específica ${ }^{35}$ tanto en la Unión Europea como a nivel internacional.

32. Dado que el Derecho Marítimo no constituye una rama del Derecho completamente autónoma ${ }^{36}$, deberemos acudir a las normas de Derecho Procesal general ${ }^{37}$ que resuelven los problemas de

${ }^{31}$ Entre las condiciones innegociables del contrato de transporte, se encuentra la cláusula de jurisdicción inserta en conocimientos de embarque. Sobre dicha cláusula, ni el cargador ni el destinatario de las mercancías pueden exigen que el porteador renuncie a la misma o que la modifique para que sea más conveniente para aquéllos. Para el porteador las ventajas de estas cláusulas serían: centralización de reclamaciones, ahorro de costes procesales, reglas procesales conocidas, mayor confianza en los tribunales de su país y uso de su lengua en el procedimiento. En este sentido, vid. E. Sierra Noguero, "Las cláusulas de jurisdicción en los conocimientos de embarque de las líneas regulares de la navegación”, en F. Martínez Sanz / Ma. V. Petit LaVall (Dirs.), Aspectos jurídicos y económicos del transporte: hacia un transporte más seguro, sostenible y eficiente, Universidad Jaime I, Valencia, 2007, p. 796.

${ }^{32}$ M. Albaladejo, Derecho Civil II. Derecho de Obligaciones. Edisofer, Madrid, 2011, pp. 435 y 436.

33 Wolters Kluwer. "Contrato de adhesión”. [Consultado el 04/01/2019]. Acceso en: http://guiasjuridicas.wolterskluwer. es/Content/Documento.aspx?params=H4sIAAAAAAAEAE1OQU4DMQx8DblUQmkrIXHIZSm3CiFYq169idlEBAdiZ9v9f V22ByxZHo1HM_PbsM49nsX5Q1JByirgCkJETnfN2s8tGZ6p0Pzt-trQCAzsrAEvDfKueLe-4jRhD4PypQas3axIikB-Q3abreFYTi8wpREkFeqgL14pBPd8tNdZb-zDo5mwsgrcIY1IgiamMe51ZdEzQvXxFUZ0-8QC6t6yQCh8D_xzNpm-tNH7n-qWwBk3Rjyf3bx6ZqIZg1Cy8_4rHcHgk-QkcKt5QX_8VJFIgEAAA==WKE.

34 J. L. Gabaldón García / J. Ma. Ruiz Soroa, Manual de Derecho de la navegación marítima. Marcial Pons, Madrid, 2006, p. 920; y J. L. Gabaldón García, Curso de Derecho marítimo internacional, Marcial Pons, Madrid, 2016, pp. 888 y 889.

${ }^{35}$ En cuanto a la falta de normativa específica sobre la determinación de la competencia judicial internacional en Derecho Marítimo y la prelación entre normas que se deben aplicar para determinarla, resulta de gran utilidad práctica, por la claridad y brevedad del juzgador a quo, el Auto de 11 de octubre de 2006 del Juzgado de lo Mercantil núm. 4 de Barcelona, FFJJ. 4 y 5. Sobre la idea de falta de normativa específica, aunque en términos generales sobre la autonomía legislativa del Derecho Marítimo, vid. J. L. Gabaldón García, Curso..., cit., pp. 39 y 40.

${ }^{36}$ L. Fontestad Portalés, Conocimiento... cit., epígrafe III, apdo. 2. b) (versión electrónica); y C. I. Cordero Álvarez, "La cláusula atributiva de jurisdicción en el conocimiento de embarque", Anuario Jurídico y Económico Escurialense, 2008 , p. 202.

${ }^{37}$ En su Informe al Anteproyecto de Ley General de Navegación Marítima de 2006, el Consejo General del Poder Judicial señaló que "no existe en nuestro sistema jurídico nada parecido a un Derecho Marítimo procesal, es decir, unas normas procedimentales especiales para los conflictos atenientes a la navegación marítima. Existen (...) algunas particularidades concretas 
competencia y también a las normas concretas de Derecho sustantivo para ubicar la materia objeto de este trabajo. Además, deberemos tener en cuenta la primacía del Derecho Internacional ${ }^{38}$ (tanto de la Unión Europea ${ }^{39}$ como de otras organizaciones internacionales, así como tratados bilaterales en los que España sea parte) sobre el Derecho de origen interno.

33. Esta idea ya ha sido apuntada por GABALDón GARCía al señalar que, mientras en algunos ordenamientos existen códigos o leyes marítimas con una importante parte procesal (p.ej. Italia en los arts. 578 a 696 del Codice della Navigazione $)^{40}$, dotada de cierta autonomía respecto al Derecho procesal común, en otros la normativa aplicable a los procedimientos marítimos se encuentra en las grandes leyes procesales comunes ${ }^{41}$.

34. En este sentido podemos decir, siguiendo a Fontestad Portalés ${ }^{42}$, que son tres los criterios o niveles que debemos considerar a la hora de determinar la competencia judicial internacional de nuestros tribunales, así como los requisitos que en cada caso se exija para prorrogar la competencia judicial internacional de los tribunales de un Estado.

35. En primer lugar, deberemos comprobar si existen Convenios internacionales específicos que regulen el transporte marítimo de mercancías (en nuestro caso el Convenio de Bruselas de 25 de agosto de 1924 sobre unificación de ciertas reglas en materia de conocimiento de embarque). En segundo lugar, tendremos que estar a las disposiciones del Derecho de la UE que determinen de modo general la competencia judicial internacional (actualmente el Reglamento (UE) núm. 1215/2012 del Parlamento Europeo y del Consejo de 12 de diciembre de 2012 relativo a la competencia judicial, el reconocimiento y la ejecución de resoluciones judiciales en materia civil y mercantil (refundición)) y, por último, deberemos acudir a las normas internas de Derecho español sobre competencia judicial internacional (Ley Orgánica 6/1985, de 1 de julio, del Poder Judicial ${ }^{43}$ y Ley 1/2000, de 7 de enero, de Enjuiciamiento Civil) ${ }^{44}$ cuando resulten aplicables ${ }^{45}$.

\section{La prórroga de la competencia con carácter general en la Unión Europea}

36. Por lo que respecta al Derecho de la UE los requisitos formales de validez de los acuerdos de prórroga de la jurisdicción en el ámbito civil-mercantil ${ }^{46}$, también llamados de atribución de compe-

(...), pero no un sistema de Derecho Procesal maritimo en sentido propio". Para la consulta de esta cita y su explicación vid. E. SAnjuán, "Especialidades procesales en la nueva Ley de Navegación Marítima", en A. B. Campuzano / E. Sanjuán (Dirs.), Comentarios a la Ley de Navegación Marítima. Tirant Lo Blanch, Valencia, 2016, pp. 483 y ss.

${ }_{38}$ En nuestro Derecho de fuente interna la superioridad del Derecho Internacional, en cuanto a lo que interesa en el presente trabajo, viene determinada por el art. 96.1 CE, 1.5 CC (entendido en sentido positivo), 21.1 LOPJ, 36.1 LEC y por los arts. 2 y 468 LENMAR. También debemos tener en cuenta los arts. 26 y 27 de la Convención de Viena sobre derecho de los tratados. En el seno de la UE, la primacía de las normas que emanan de la misma viene determinada, además de por los citados artículos de la CVDT, por los arts. 4 TUE y 288 TFUE. Se puede constatar, como se ha puesto de manifiesto en el cuerpo del trabajo, que el objeto de nuestro estudio requiere de normas tanto generales como específicas, nacionales e internacionales.

${ }^{39}$ Para entender mejor la primacía del Derecho de la UE, léanse las SSTJUE de 12 de julio de 1964, Costa v. ENEL, 6/64; y de 10 de octubre de 1973, Polito, 43/71, entre otras muchas.

40 Gazzetta Ufficiale del 18 aprile 1942, n. 93.

41 J. L. Gabaldón García, Curso..., cit., pp. 40 y 887.

42 L. Fontestad Portalés, Conocimiento..., cit., (versión electrónica).

${ }^{43}$ BOE núm. 157, de 2 de julio de 1985. Referencia: BOE-A-1985-12666.

${ }^{44}$ BOE núm. 7, de 8 de enero de 2000. Referencia: BOE-A-2000-323.

${ }^{45}$ Conviene aclarar ya en este punto que las normas sobre competencia judicial internacional que recogen los arts. 22 y ss. de la LOPJ se aplicarán en el caso objeto de estudio cuando la cláusula de atribución de competencia en el conocimiento de embarque designe como tribunal competente un tribunal de un Estado no miembro de la UE, o que no es miembro del Convenio de Lugano de 2007, y ello sin perjuicio de la eventual existencia de un convenio internacional bilateral entre España y otro tercer Estado.

${ }^{46}$ En el contexto de este trabajo se entiende por jurisdicción la competencia internacional que tiene un Estado para conocer de un determinado asunto. No se debe confundir con el concepto de jurisdicción por razón de la materia, pues no hay dudas sobre la mercantilidad de las relaciones que originan estas cláusulas y, por tanto, tampoco hay duda sobre el orden jurisdiccional al que le correspondería enjuiciar los supuestos. El transporte marítimo internacional de mercancías, se trata en todo caso de 
tencia o cláusulas flotantes de jurisdicción en Derecho Marítimo, están regulados en la actualidad por el art. 25 del Reglamento (UE) núm. 1215/2012 del Parlamento Europeo y del Consejo de 12 de diciembre de 2012 relativo a la competencia judicial, el reconocimiento y la ejecución de resoluciones judiciales en materia civil y mercantil (refundición) ${ }^{47}$ (en adelante Reglamento 1215/2012) ${ }^{48}$.

37. Se trata, en consecuencia, de una norma de Derecho derivado, vinculante, típica, obligatoria en todos sus elementos y directamente aplicable en todos los Estados miembros de la UE (art. 288 del TFUE y 81 del Reglamento 1215/2012) $)^{49}$. El artículo de referencia en el presente estudio es el que se transcribe a continuación, subrayando aquellas partes que nos interesan, para ir analizándolas poco a poco.

\section{"SECCIÓN 7}

\section{Prórroga de la competencia}

Artículo 25

1. Si las partes, con independencia de su domicilio, han acordado que un órgano jurisdiccional o los órganos jurisdiccionales de un Estado miembro sean competentes para conocer de cualquier litigio que haya surgido o que pueda surgir con ocasión de una determinada relación jurídica, tal órgano jurisdiccional o tales órganos jurisdiccionales serán competentes, a menos que el acuerdo sea nulo de pleno derecho en cuanto a su validez material según el Derecho de dicho Estado miembro. Esta competencia será exclusiva, salvo pacto en contrario entre las partes. El acuerdo atributivo de competencia deberá celebrarse:

a) $[\ldots]$;

b) $[\ldots], o$

c) en el comercio internacional, en una forma conforme a los usos que las partes conozcan o deban conocer y que, en dicho comercio, sean ampliamente conocidos y regularmente observados por las partes en los contratos del mismo tipo en el sector comercial considerado.

2. […

3. $[\ldots]^{50}$.

4. No surtirán efecto los acuerdos atributivos de competencia [...] si son contrarios a las disposiciones de los artículos 15, 19 o 23, o si excluyen la competencia de órganos jurisdiccionales exclusivamente competentes en virtud del artículo 24.

\section{5. […"}

38. Anteriormente, con base en el art. 220 del Tratado de Roma, era el art. 17 del Convenio relativo a la competencia judicial y la ejecución de resoluciones judiciales en materia civil y mercantil, hecho en Bruselas el 27 de septiembre de 1968 (en adelante el Convenio de Bruselas de 1968) ${ }^{51}$, modificado sucesivamente por la adhesión de nuevos Estados miembros de la UE a este Convenio, el que establecía dichos requisitos formales ${ }^{52}$.

un contrato mercantil, pues hace posible el desarrollo de actividades empresariales, tanto del porteador, como del destinatario de las mercancías. Es, en fin, un contrato que integra la actividad productiva o comercial de las partes que intervienen en estas relaciones, lo que excluye la condición de consumidor o usurario del transporte marítimo.

47 También conocido en Derecho Internacional Privado como Reglamento Bruselas I bis.

${ }^{48}$ DOUE, núm. L 351, de 20 de diciembre de 2012.

${ }^{49}$ Para un análisis doctrinal y jurisprudencial del reglamento como acto vinculante de la UE, vid. A. Mangas Martín / D. J. Liñan Nogueras, Instituciones y Derecho de la Unión Europea, Tecnos, Madrid, 2016, pp. 370-373.

${ }^{50}$ Nótese que este apartado ahora se refiere a los documentos constitutivos de un trust que otorgan competencia al tribunal o tribunales de un Estado miembro, no al hecho que se daba en el Reglamento 44/2001 cuando ninguna de las partes que hubieren celebrado un acuerdo estaba domiciliada en la UE.

${ }^{51}$ DOUE, núm. C 027, de 26 de enero de 1998.

${ }^{52}$ La SAP de Barcelona, de 2 de junio de 2004, FJ. 6 (Rec. 709/2002) y el Auto núm. 288/2005, de 28 de noviembre, FJ. 9, de la misma Audiencia, entre otras muchas resoluciones, realizan un breve análisis de la evolución del Convenio, señalan- 
39. El Convenio de Bruselas de 1968, que había sentado las bases de un verdadero espacio judicial europeo ${ }^{53}$, fue sustituido por el Reglamento (CE) núm. 44/2001 del Consejo de 22 de diciembre de 2000 relativo a la competencia judicial, el reconocimiento y la ejecución de resoluciones judiciales en materia civil y mercantil (Reglamento Bruselas I) ${ }^{54}$, en vigor desde el 1 de marzo de 2002, cuyo art. 23 reprodujo exactamente el art. 17 del Convenio de Bruselas de 1968, aunque se sacaron contenidos de este artículo que en el Reglamento 44/2001 se vieron reflejados en otros artículos, añadiendo además el numeral 3 a petición del Reino Unido.

40. Por otro lado, en paralelo al Reglamento $1215 / 2012^{55}$ y tomando como referencia el Convenio de Bruselas de 1968, se adoptó el Convenio relativo a la competencia judicial y a la ejecución de resoluciones judiciales en materia civil y mercantil, celebrado en Lugano el 16 de septiembre de 1988 (en adelante el Convenio de Lugano), modificado por Decisión del Consejo de 15 de octubre de 2007 relativa a la firma en nombre de la Comunidad del Convenio relativo a la competencia judicial, el reconocimiento y la ejecución de resoluciones judiciales en materia civil y mercantil (en adelante el Convenio de Lugano de 2007). Dicho Convenio regula en su art. 23 los acuerdos de prórroga de la competencia. El artículo exige actualmente que al menos una de las partes esté domiciliada en un Estado vinculado por el mismo, pero en cuanto a los requisitos formales de la prórroga de jurisdicción, son los mismos que establece el art. 25 del Reglamento 1215/2012. El art. 23 del Convenio de Lugano de 2007 presenta actualmente una redacción similar a la del art. 25 del Reglamento 1215/2012, salvo las diferencias que se irán matizando.

41. De una confrontación a primera vista de los cuatro artículos mencionados en este apartado y teniendo en cuenta el objeto de estudio del presente trabajo, podemos establecer las siguientes conclusiones que nos valdrán durante todo el análisis que haremos para entender la forma en que se debe dar la prórroga y sus límites materiales.

42. Dichas conclusiones son las siguientes:

$1^{\mathrm{a}}$. Los requisitos formales de la prórroga no han cambiado desde que el Convenio de Bruselas de 1968 fue modificado.

$2^{\text {a }}$. Se mantienen también desde ese Convenio unos supuestos especiales de protección, que veremos más adelante en relación con los límites a la autonomía jurisdiccional de las partes.

$3^{\mathrm{a}}$. Se mantienen, asimismo, una serie de competencias exclusivas que no pueden ser objeto de prórroga jurisdiccional.

43. Todas estas conclusiones deben ser tenidas en cuenta también durante la lectura y comprensión de la doctrina y la jurisprudencia sobre los acuerdos de prórroga de jurisdicción en la UE, ya sea para el tema que nos ocupa como en general.

\section{Régimen jurídico aplicable en la actualidad. El Reglamento 1215/2012 y el Convenio de Lugano de 2007}

44. Como hemos indicado ya, en la actualidad la norma de Derecho de la UE que establece los requisitos para la validez formal de los acuerdos de prórroga de jurisdicción es el art. 25 del Reglamento

do que en un primer momento era necesaria la forma escrita o verbal con confirmación escrita del convenio de atribución de competencia, es decir, el apdo. a) del art. 17 del Convenio de Bruselas de 1968. Posteriormente, el Convenio de adhesión 9 de octubre de 1978 relativo a la adhesión del Reino de Dinamarca, Irlanda y del Reino Unido e Irlanda del Norte, y el Convenio de 26 de mayo de 1989 relativo a la adhesión del Reino de España y de la República Portuguesa, añadieron los apdo. b) y c), que se han mantenido en los Reglamentos que han sucedido a dicho Convenio.

${ }_{53}$ L. Moreno Blesa, "Las novedades introducidas en el espacio judicial europeo con la reforma del Reglamento Bruselas (1)”, Actualidad Civil, núm. 1, 2015.

${ }^{54}$ DOUE, núm. L 012, de 16 de enero de 2001.

55 Vid. art. 73.1 del Reglamento 1215/2012 y el art. 64.1 y el Preámbulo del Convenio de Lugano de 2007. 
$1215 / 2012$, que es el instrumento general de la UE en materia de competencia judicial internacional ${ }^{56}$, y el art. 23 del Convenio de Lugano de $2007^{57}$, aunque no es una norma propiamente de la UE.

45. Dicho Reglamento prevalece sobre la legislación interna de los Estados miembros como consecuencia de la naturaleza del mismo como acto normativo de la UE y dentro del territorio de la mis$\mathrm{ma}^{58}$. Responde a la necesidad de crear un cuerpo legislativo uniforme para fomentar la seguridad jurídica y la previsibilidad en caso de litigios o desacuerdos, ya que las normas internas de Derecho Internacional Privado varían de un Estado a otro y esto podría dificultar enormemente el funcionamiento fluido y correcto del mercado interior de la UE, así como desincentivar las relaciones con terceros Estados ${ }^{59}$.

46. Todo ello se debe a que los principios de libre circulación de mercancías, servicios, capitales y personas originan actividades mercantiles y desplazamientos de ciudadanos por toda la UE. Es, como acertadamente ha señalado MoRENo BlESA, una necesidad derivada de unas relaciones humanas cada vez más complejas y, por ello, el Derecho precisa ser global y armonizado ${ }^{60}$. Además, las reformas operadas buscan también progresar en el objetivo de ofrecer a los ciudadanos de la UE un espacio de libertad, seguridad y justicia ${ }^{61}$. En este trabajo nos vamos a centrar en el art. 25 del Reglamento 1215/2012, ya que en la mayoría de las cláusulas de jurisdicción contenidas en conocimientos de embarque se designa un tribunal de la $\mathrm{UE}^{62}$ o que forma parte del Convenio de Lugano de 2007.

\section{A) Ámbito material}

47. El art. 1.1 del Reglamento 1215/2012 dispone que dicha norma europea "se aplicará en materia civil y mercantil con independencia de la naturaleza del órgano jurisdiccional". Debemos recordar que el Reglamento no cubre todas las materias civiles y mercantiles, pues "debe abarcar lo esencial"63 de aquéllas, lo que determina la existencia de materias excluidas expresamente ${ }^{64} \mathrm{y}$ esto hace que nos planteemos si el objeto de nuestro estudio está excluido o no de su ámbito material de aplicación.

48. Por lo que respecta a las cláusulas de atribución de competencia insertas en conocimientos de embarque, podemos decir que éstas tienen naturaleza mercantil, pues se insertan en el marco de contratos internacionales de transporte de mercaderías celebrados entre operadores y empresas que habitualmente actúan en el comercio internaciona ${ }^{65}$. De esta forma, tenemos a porteadores acostumbrados a realizar transportes internacionales por mar y a comerciantes o empresas habituadas a actuar en el comercio internacional (exportando o importando sus productos).

49. De lo ahora expuesto, podemos concluir que la existencia y configuración de estas cláusulas no plantea problemas por lo que respecta al ámbito de aplicación material del Reglamento 1215/2012,

56 J. C. Fernández Rozas / P. A. De Miguel Asensio, Derecho internacional privado: textos y materiales. Aranzadi, Madrid, 2017 (versión electrónica).

${ }^{57}$ Estas normas forman la Cooperación judicial en materia civil de la UE y tienen su fundamento jurídico de Derecho de la UE en los arts. 67.4 y 81.1 y 2, letras a), c) y e) del TFUE (cuyo antecedente directo es el art. 65 del Tratado de la Comunidad Europea) y en los Protocolos núm. 21 y 22 del Tratado de Lisboa.

${ }_{58}$ En este sentido se pronunció la STJCE Coreck (C-387/98).

${ }^{59}$ Unión Europea. “Cooperación judicial en materia civil en la Unión Europea. Guía para juristas”, 2015, pp. 5 y 11 [Consultado el 13/01/2019]. Acceso en: https://e-justice.europa.eu/content_ejn_s_publications-287-es.do.

${ }^{60}$ L. Moreno Blesa, "Las novedades...", cit., p. 2.

${ }^{61}$ Vid. considerando (3) y (4) del Reglamento 1215/2012.

${ }^{62}$ Habitualmente la High Court of Justice of London, o tribunales franceses o neerlandeses.

${ }^{63}$ Vid. considerando (10) del Reglamento 1215/2012.

${ }^{64}$ P. Maestre CASAS, "Reglamento (UE) n. ${ }^{0}$ 1215/2012 del Parlamento Europeo y del Consejo, de 12 de diciembre de 2012, relativo a la competencia judicial, el reconocimiento y la ejecución de resoluciones judiciales en materia civil y mercantil", Ars Iuris Salmanticensis, vol. 1, 2013, p. 193.

${ }^{65}$ También podemos considerar como operadores habituados a actuar en estas relaciones mercantiles a las aseguradoras que se subrogan en la posición de su asegurado cuando se verifica un daño a las mercancías y les abonan la indemnización correspondiente. Es importante señalar, sin embargo, que no es que las aseguradoras estén habituadas a actuar en el comercio marítimo internacional, sino que están habituadas a asegurar a operadores en dicho sector del comercio internacional, que sí que lo están. 
pues entran en el marco de relaciones mercantiles internacionales no excluidas de su ámbito de aplicación. El Reglamento 1215/2012 afecta al transporte internacional de mercancías en régimen de conocimiento de embarque al no haber sido éste excluido expresamente de su ámbito material de aplicación (SS del Tribunal Supremo núm. 804/2007, de 5 de julio, FJ. 2; y del Juzgado de lo Mercantil núm. 1 de Valencia, de 10 de abril de 2015, FJ. 2; y Autos de la AP de Las Palmas núm. 24/2007, de 1 de febrero, FJ. 2, y de Pontevedra núm. 30/2008, de 14 de febrero, FJ. 3, entre otras muchas resoluciones). La misma conclusión podemos extrapolar al Convenio de Lugano de 2007, cuyo art. 1 es esencialmente igual al art. 1 del Reglamento.

50. Por tanto, las cláusulas de atribución de competencia insertas en conocimientos de embarque, como veremos en los límites a la autonomía de la voluntad, no tienen prácticamente ningún límite material más allá de los requisitos formales del art. 25 y un límite general que estudiaremos más adelante.

\section{B) Ámbito temporal}

51. El ámbito de aplicación temporal irretroactivo de este Reglamento puede hacer que nos cuestionemos, como hacía $\operatorname{RocA}^{66}$, la validez interpretativa de la doctrina y la jurisprudencia que va a ser estudiada y citada en este trabajo, ya que algunas sentencias datan de las décadas de los años 70 y 80 . Sin embargo, tanto la doctrina como la jurisprudencia estudiadas son plenamente aplicables incluso hoy, pues los requisitos formales de la prórroga de la competencia no han cambiado, como quedó de manifiesto al estudiar la evolución de los artículos que han ido regulando esta cuestión, desde el Convenio de Bruselas de 1968 hasta el Reglamento 1215/2012 y el Convenio de Lugano de 2007. Esto hace que muchas sentencias y artículos doctrinales se refieran todavía a dicho Convenio e, incluso, al ya derogado Reglamento 44/2001, si la acción fue iniciada antes del 10 de enero de 2015.

52. Por lo que respecta al reformado Convenio de Lugano de $2007^{67}$, entró en vigor en Noruega y en la UE, incluyendo a Dinamarca, el 1 de enero de 2010; en Suiza el 1 de enero de 2011 y en Islandia el 1 de mayo de 2011.

\section{C) Ámbito territorial}

53. En el ámbito territoria ${ }^{68}$, el Reglamento $1215 / 2012$ supuso un importantísimo cambio, pues se modificó del numeral 1 del art. 23 del Reglamento 44/2001 la frase "cuando al menos una de las partes tuviera su domicilio en un Estado miembro de la UE"69. Esto significaba que cuando ambas partes estuvieran domiciliadas en Estados que no eran miembros de la UE, el tribunal del Estado miembro designado en la cláusula de sumisión podía, de acuerdo con su Derecho interno ${ }^{70}$, aceptar o declinar su

${ }^{66}$ M. Roca, "El impacto del Reglamento 1215/2012 sobre el Derecho Marítimo”. 2015. [Consultado el 04/01/2019]. Acceso en: http://www.derechomaritimo.info/wp-content/uploads/El-Impacto-del-Reglamento-1215-2012-sobre-el-DerechoMar\%C3\%ADtimo.pdf. También en este sentido resulta muy clarificador el prólogo de J. L. Gabaldón GarCía a J. L. PULIDO Begines, Curso de Derecho de la Navegación Marítima, Tecnos, Madrid, 2015, pp. 19- 21. Gabaldón García señala que la aparición de la LENMAR no puede suponer la nulidad sobrevenida de toda la literatura jurídica precedente a la misma, idea que podemos extrapolar a lo que aquí tratamos ahora.

${ }^{67}$ Vid. el art. 63.1 del Convenio de Lugano de 2007 y Unión Europea. “Cooperación judicial...”, cit., p. 12.

${ }^{68}$ El art. 68.1 del Reglamento 1215/2012 (mismo artículo del Reglamento 44/2001), y en base al art. 355 TFUE (antiguo art. 299 del Tratado de la Comunidad Europea), supone su aplicación en todos los territorios de Francia, incluyendo los del Ultramar; en Reino Unido se aplica a Gibraltar, pero no a las Islas Mann, Islas del Canal o islas anglonormandas; en España se aplica a todo el territorio nacional, incluyendo Ceuta y Melilla, las Islas Canarias y las Islas Baleares; en Portugal se aplica a todo el territorio nacional, incluyendo las Azores y Madeira; y por último, se aplica en Finlandia incluyendo las islas Aland.

${ }^{69}$ Decía el ahora suprimido art. 1.3 del Reglamento 44/2001: "En el Presente Reglamento por la expresión «Estado miembro» se entenderá cualquier Estado miembro [de la UE] excepto Dinamarca".

70 I. Dízz-Picazo Giménez / A. De La Oliva Santos, Derecho Procesal Civil. El proceso de declaración, Centro de Estudios Ramón Areces, Madrid, 2003, p. 67; L. CAPIEL, "Novedades en el Reglamento Bruselas I Refundido", Actualidad Jurídica Uría Menéndez, núm. 40, 2015, p. 143; y C. Rosende VILlaR, "Principales novedades del Reglamento 1215/2012, de 12 de diciembre de 2012, relativo a la competencia judicial, el reconocimiento y la ejecución de resoluciones judiciales en materia civil y mercantil”, Revista Aranzadi Unión Europea, núm. 11, 2014, apdo. I y II. C (versión electrónica). 
competencia $\mathrm{y}$, es en este último caso, cuando los demás tribunales de los Estados miembros podían declararse competentes; mientras que si ambas partes, o al menos una de ellas, estaban domiciliadas en Estados que eran miembros de la UE, el tribunal designado por la cláusula de atribución de competencia no podía declinar su competencia, si el acuerdo de atribución era válido conforme al Reglamento, y los demás tribunales de los Estados miembros debían abstenerse de conocer el litigio.

54. Como consecuencia de la eliminación de la referencia al domicilio de las partes se eliminó también el numeral 3 del art. 2371, quedando la redacción el art. 25.1 del Reglamento 1215/2012 de la siguiente manera:

"1. Si las partes, con independencia de su domicilio, han acordado que un órgano jurisdiccional o los órganos jurisdiccionales de un Estado miembro sean competentes para conocer de cualquier litigio que haya surgido o que pueda surgir con ocasión de una determinada relación jurídica, tal órgano jurisdiccional o tales órganos jurisdiccionales serán competentes [...]”.

55. También la modificación operada en el ámbito territorial de aplicación del Reglamento ha hecho que la doctrina se haya planteado si en base a dicha modificación podíamos seguir aplicando las sentencias del Tribunal de Justicia de la Unión Europea ${ }^{72}$ (en adelante TJUE) ${ }^{73}$ a supuestos actuales, concluyendo satisfactoriamente que sí, pues antes bastaba que una de las partes estuviese domiciliada, pero ahora se ha eliminado dicho requisito.

56. En consecuencia, lo relevante en la actualidad para determinar los efectos de la prórroga de la competencia ya no es que concurran acumulativamente los requisitos que exigía el Reglamento 44/2001 y anteriormente el Convenio de Bruselas de 1968, a saber: primero, que al menos una de las partes estuviese domiciliada en un Estado miembro de la UE, domiciliación que debía verificar el órgano jurisdiccional nacional en cuestión; y segundo, que la cláusula que contuviese el acuerdo de atribución de competencia designase un tribunal de un Estado miembro de la UE (STJCE Coreck, apdos. 17 y 19).

57. Ahora basta únicamente que se verifique el segundo, es decir, que el tribunal designado en el acuerdo de prórroga de la competencia sea un tribunal de cualquier Estado miembro de la UE. Así las cosas, puede ser que las dos partes estén domiciliadas en dos Estados diferentes de la UE, que una lo esté y que otra no (como suele ser lo más habitual), o que ninguna de las dos estén domiciliadas en la UE, con los mismos efectos de prórroga; es decir, ya no se realiza el tratamiento diferenciado que hacía el art. 23.3 del Reglamento 44/2001, como ha señalado De Miguel Asensio ${ }^{74}$; y que constituía un doble requisito que nuestros tribunales aplicaban hasta hace muy poco para determinar la aplicación del Reglamento 44/2001 (anteriormente el Convenio de Bruselas de 1968) ${ }^{75}$. Se ha producido lo que PADRós $\mathrm{AMAT}^{76}$ ha denominado como el "eurocentrismo", es decir, el desplazamiento de las normas internas en supuestos en que ninguna de las partes esté domiciliada en un Estado de la UE.

\footnotetext{
71 Vid. art. 23.3 del Reglamento 44/2001.

${ }^{72}$ Nos referimos fundamentalmente a tres sentencias del TJUE que interpretan el art. 17 del Convenio de Bruselas de 1968, aplicado a cláusulas de atribución de competencia en conocimientos de embarque, y que serán analizadas más adelante.

${ }^{73}$ El TJUE pasó a denominarse de tal forma en 2009. Antes, la denominación de esta institución de la UE era "Tribunal de Justicia de la Comunidad Europea" (TJCE). Por esta razón, a veces nos referimos a esta institución como "TJCE” y otras como "TJUE", sabiendo que nos referimos a la misma en ambos casos.

${ }^{74}$ P. A. De Miguel Asensio, "El nuevo Reglamento sobre competencia judicial y reconocimiento de resoluciones judiciales", La Ley, núm. 8013, 2013, apdo. IV.

${ }^{75}$ H. Aguilar Grieder, "Alcance de la regulación europea relativa a la competencia judicial internacional en materia civil y mercantil en el marco del nuevo reglamento "Bruselas I Bis" (1215/2012): una apuesta parcialmente frustrada", Revista Aranzadi Doctrinal, núm. 9, 2015 (versión electrónica).

${ }^{76}$ B. PAdRós AmAT, "Novedades el Reglamento "Bruselas I bis" sobre competencia judicial, reconocimiento y ejecución de títulos ejecutivos extranjeros". 2015. [Consultado el 04/01/2019]. Acceso en: http://www.abogacia.es/2015/02/11/novedadesdel-reglamento-bruselas-i-bis-sobre-competencia-judicial-reconocimiento-y-ejecucion-de-titulos-ejecutivos-extranjeros/
} 
58. Mención especial merecen los casos de Dinamarca, Irlanda y Reino Unido. Estos países gozan de unos regímenes especiales ${ }^{77}$ que les permiten participar o no en la adopción de instrumentos como los que estamos estudiando aquí.

59. En el caso del Reino Unido y de Irlanda, estos países decidieron participar desde el inicio en la adopción y aplicación del Reglamento $44 / 2001^{78} \mathrm{y}$, posteriormente, decidieron participar en la adopción y aplicación del Reglamento 1215/2012, como quedó de manifiesto en ambos Reglamentos ${ }^{79}$.

60. El caso de Dinamarca es aún más particular. En un primer momento, el Reglamento 44/2001 no le era aplicable ni estaba sujeta al mismo, como se indicaba en el considerando (21) de dicho Reglamento, y se le seguía aplicando el Convenio de Bruselas de $1968^{80}$. Sin embargo, posteriormente, en base al Acuerdo de 19 de octubre de 2005 entre la Comunidad Europea y el Reino de Dinamarca relativo a la competencia judicial, el reconocimiento y la ejecución de resoluciones en materia civil y mercantil (en adelante el Acuerdo) ${ }^{81}$, Dinamarca decidió aplicar las disposiciones del Reglamento 44/2001. Por otro lado, en el art. 3.2 del Acuerdo se establecía que cuando se realizasen modificaciones al Reglamento 44/2001, Dinamarca debería notificar a la Comisión Europea su intención de aplicar o no dichas modificaciones. Es por esto que cuando vio la luz el Reglamento 1215/2012 tampoco resultó aplicable a Dinamarca ${ }^{82}$. Por ello, conforme al art. 3.2 del Acuerdo, Dinamarca notificó mediante carta de 20 de diciembre de 2012 dirigida a la Comisión Europea su decisión de aplicar el nuevo Reglamento modificativo del Reglamento 44/2001, originando un nuevo Acuerdo de 21 de marzo de $2013^{83}$.

61. Por lo que respecta al ámbito de aplicación territorial del Convenio de Lugano, dispone su art. 23 que:

"1. Si las partes, cuando al menos una de ellas tuviere su domicilio en un Estado vinculado por el presente Convenio ${ }^{84}$, hubieren acordado que un tribunal o los tribunales de un Estado vinculado por el presente Convenio fueren competentes para conocer de cualquier litigio que hubiere surgido o que pudiere surgir con ocasión de una determinada relación jurídica, tal tribunal o tales tribunales serán competentes [...]" (subrayado nuestro).

62. Esto supone que el Convenio se aplique entre los Estados miembros de la UE y Suiza, Noruega e Islandia, o entre estos Estados y un tercer Estado, cuando la cláusula de atribución de competencia se refiera a un tribunal de uno de esos Estados y al menos una de las partes esté domiciliada en uno de ellos, sin que el tribunal designado pueda declinar su competencia si el acuerdo es válido conforme al Convenio ${ }^{85}$. Sin embargo, el art. 23 del Convenio de Lugano mantiene un numeral 3 en la línea del art. 23.3 del Reglamento 44/2001, cuando ninguna de las partes esté domiciliada en un Estado vinculado por el Convenio:

"3. Cuando ninguna de las partes que hubieren celebrado un acuerdo de este tipo estuviere domiciliada en un Estado vinculado por el presente Convenio, los tribunales de los demás Estados vinculados por el presente Convenio solo podrán conocer del litigio cuando el tribunal o los tribunales designados hubieren declinado su competencia".

\footnotetext{
${ }^{77}$ Unión EUROPEA. "Cooperación judicial...", cit., p. 6.

${ }^{78}$ H. Aguilar Grieder, “Alcance...”, cit., (versión electrónica).

79 Vid. considerando (20) del Reglamento 44/2001 y considerando (40) del Reglamento 1215/2012.

80 Vid. considerando (22) del Reglamento 44/2001.

${ }^{81}$ DOUE, núm. L 299, de 16 de noviembre de 2005.

82 Vid. considerando (41) del Reglamento 1215/2012.

${ }^{83}$ DOUE, núm. L 79, de 21 de marzo de 2013. También, vid., DOUE, núm. L 182, de 10 de julio de 2015.

${ }^{84}$ Los apdos. 1 y 3 del art. 23 del Convenio de Lugano deben ser leídos teniendo en cuenta el art. 1.3 del mismo Convenio: "Con arreglo al presente Convenio, el término «Estado vinculado por el presente Convenio» se refiere a cualquier Estado que es Parte contratante del presente Convenio o a un Estado miembro de la Comunidad Europea. También puede referirse a la Comunidad Europea".

${ }^{85}$ Por ejemplo, una cláusula de atribución de competencia a un tribunal suizo entre una naviera domiciliada en Suiza y una empresa domiciliada en China, o bien, una en que se designase un tribunal islandés estando una parte domiciliada en Francia y otra en Islandia.
} 
63. Como ocurría antes en el territorio de la UE cuando estaba vigente el Reglamento 44/2001 ${ }^{86}$, cuando dos Estados no vinculados por el Convenio de Lugano de 2007 designen un tribunal de Suiza, Noruega o Islandia, aquél podrá aceptar o declinar su competencia de acuerdo con su Derecho interno y si la declina, entonces los demás tribunales vinculados por el Convenio podrán entrar a conocer el litigio ${ }^{87}$.

\begin{tabular}{|c|c|c|}
\hline Domicilio de las partes & $\begin{array}{l}\text { Reglamento europeo/ } \\
\text { Convenio de referencia }\end{array}$ & $\begin{array}{l}\text { Artículo regulador de los } \\
\text { requisitos formales de la } \\
\text { prórroga de la competencia }\end{array}$ \\
\hline $\begin{array}{l}\text { Parte domiciliada en la UE/parte no } \\
\text { domiciliada en la UE }\end{array}$ & \multirow{3}{*}{$\begin{array}{l}\text { Reglamento } \\
1215 / 2012\end{array}$} & \multirow{3}{*}{25.1} \\
\hline Partes domiciliadas en la UE & & \\
\hline Partes domiciliadas fuera de la UE & & \\
\hline Partes domiciliadas en Suiza, Noruega o Islandia & \multirow{4}{*}{$\begin{array}{l}\text { Convenio de Lugano } \\
\text { de } 2007\end{array}$} & \multirow{3}{*}{23.1} \\
\hline $\begin{array}{l}\text { Parte domiciliada en la UE/parte } \\
\text { domiciliada en Suiza, Noruega o Islandia }\end{array}$ & & \\
\hline $\begin{array}{l}\text { Parte domiciliada en Suiza, Noruega o Islandia/ } \\
\text { parte domiciliada en un Estado no vinculado por } \\
\text { el Convenio de Lugano }\end{array}$ & & \\
\hline $\begin{array}{l}\text { Partes no domiciliadas en un Estado vinculado } \\
\text { por el Convenio de Lugano }\end{array}$ & & 23.3 \\
\hline
\end{tabular}

Fuente: elaboración propia a partir de la aplicación del ámbito territorial del Reglamento 1215/2012 y del Convenio de Lugano de 2007.

\section{Límites a la autonomía jurisdiccional de las partes}

64. Antes de entrar en otras cuestiones resulta necesario analizar si las cláusulas de atribución de competencia insertas en conocimientos de embarque son susceptibles de prórroga de competencia judicial internacional, o bien colisionan con alguna competencia exclusiva o con algún foro especial de protección.

\section{A) Consideraciones generales sobre la autonomía jurisdiccional de las partes}

65. El art. 25.4 del Reglamento 1215/2012 se limita a señalar que no surtirán efecto los acuerdos atributivos de competencia si son contrarios a los arts. 15, 19 o 23 (prórroga de la competencia en supuestos especiales de protección) o si excluyen la competencia de jurisdicciones exclusivamente competentes en base al art. 24 (competencias exclusivas).

66. La materia objeto del presente estudio es el transporte marítimo internacional de mercancías en régimen de conocimiento de embarque. Dado que habíamos dicho que se trata de una materia que no ha sido excluida del ámbito material de aplicación del Reglamento 1215/2012, al ser una materia mercantil no excluida expresamente (art. 1), concluíamos que era de aplicación dicho Reglamento.

67. Salvado el requisito de aplicación material de la norma, nos preguntamos si, aun siendo materialmente de aplicación el Reglamento 1215/2012, nos podemos encontrar ante un asunto no susceptible de prórroga de competencia o ante supuestos especiales de protección. En el primer caso, la prórroga no tendrá lugar nunca, pues los acuerdos de atribución de competencia solo pueden versar sobre foros

${ }^{86}$ Sobre las referencias al Reglamento 44/2001 y la aplicación temporal y territorial del Reglamento 1215/2012, vid. arts. 80 y 81 del Reglamento 1215/2012.

${ }^{87}$ Por ejemplo, una cláusula de atribución de competencia a un tribunal noruego entre una naviera domiciliada en República Democrática del Congo y una empresa domiciliada en Malasia. 
de competencia disponibles ${ }^{88}$. En el segundo, no es que no se permita la sumisión (expresa o tácita), sino que se condiciona al cumplimiento de ciertos requisitos ${ }^{89}$.

68. Partiendo del principio general de admisibilidad de las cláusulas de atribución de competencia (AAP de Cantabria núm. 117/2000, de 9 de junio, FJ. 2) ${ }^{90}$, vamos a estudiar los límites de la autonomía jurisdiccional de las partes en las cláusulas que son objeto de análisis en este trabajo, aplicando el sistema competencial del Reglamento $1215 / 2012^{91}$ al transporte marítimo internacional de mercancías.

\section{B) Análisis del sistema competencial del Reglamento 1215/2012 en relación con el transporte ma- rítimo internacional de mercancías}

69. Del sistema competencial del Reglamento 1215/2012 nos interesa analizar en este trabajo: competencias exclusivas, supuestos especiales de protección y la sumisión tácita como criterio de atribución de competencia.

\section{a) Competencias exclusivas}

70. El primer nivel al que debemos acudir para comprobar si es posible prorrogar la competencia, son las competencias exclusivas. Estas competencias vienen reguladas en el art. 24 del Reglamento 1215/2012. Como tales, no pueden ser excluidas por acuerdo entre las partes ${ }^{92}$, pues los Estados que asumen jurisdicción con tal carácter no reconocerán la jurisdicción de ningún otro y no darán valor a las decisiones que no sean de los tribunales del foro ${ }^{93}$. Tampoco plantean problemas los arts. 22 y 22 bis de la LOPJ, en los que no vamos a entrar aquí ${ }^{94}$.

71. Por su parte, el transporte marítimo internacional de mercancías en régimen de conocimiento de embarque no encaja en ninguna de las cinco competencias exclusivas, al no tratarse de derechos reales inmobiliarios; validez, nulidad o disolución de personas jurídicas; inscripciones en registros públicos, etc. Siguiendo nuevamente a FonTESTAD PorTAlÉs, el Reglamento 1215/2012 no presenta ninguna competencia exclusiva que afecte especialmente al transporte marítimo ${ }^{95}$.

88 J. Ma . Espinar Vicente, Doce reflexiones sobre el Derecho internacional privado español, LICEUS, Madrid, 2014, p. 38. Además, en caso de que un juez de un Estado dictase una resolución sobre una materia que es competencia exclusiva de otro Estado, aquél se arriesgaría, con gran seguridad, a que el Estado requerido no reconociese en fase de reconocimiento la resolución dictada.

${ }^{89} \mathrm{Vid}$. arts. 15, 19 y 23 del Reglamento 1215/2012 para una visión más completa de la forma en que se puede realizar la sumisión expresa en estos casos.

${ }^{90}$ Tomando como referencia el Auto de la AP de Cantabria mencionado en el cuerpo del trabajo, podemos definir el principio general de admisibilidad de las cláusulas de atribución de competencia, como aquel principio en virtud del cual los acuerdos de atribución de competencia que designen un tribunal o tribunales sito/s en un Estado/s miembro/s de la UE, son válidos y eficaces con carácter general, siempre que cumplan alguno de los requisitos formales del art. 25.1 del Reglamento 1215/2012 y no se trate de competencias exclusivas (arts. 24 y 25.4), sin perjuicio de la sumisión tácita (art. 26) y de los concretos requisitos de los supuestos especiales de protección (arts. 15, 19, y 23).

91 P. Maestre Casas, "Reglamento...", cit., pp. 194 y 195.

92 C. I. Cordero Álvarez, "Análisis metodológico de la autonomía jurisdiccional en el transporte marítimo internacional y derogatio fori”. 2007. [Consultado el 04/01/2019]. Acceso en: http://pendientedemigracion.ucm.es/info/kinesis/fori.htm., apdo. I. a).

93 J. Mª Espinar Vicente, Doce reflexiones..., cit., pp. 33 y 38.

${ }_{94} \mathrm{El}$ art. 22 LOPJ hace referencia a las competencias exclusivas de los Juzgados y Tribunales españoles y, como hemos indicado ya, no afecta al objeto de nuestro estudio. Por su parte, el art. 22 bis LOPJ señala, entre otras cuestiones, la ineficacia de los acuerdos atributivos de competencia cuando se trate de materias que sean de competencia exclusiva de la jurisdicción española y, por ello, indisponibles.

${ }^{95}$ L. Fontestad PoRTALÉs, El transporte maritimo de mercancias y sus incidencias procesales. Tesis doctoral (s.p.), Universidad de Málaga, Málaga, 2003, p. 501. En este sentido se pronuncia también el AAP de Barcelona núm. 252/2005, de 19 de octubre, FJ. 1 que, si bien está analizando una cláusula que designa el Tribunal de Distrito de Tokyo, señala que el contrato de transporte marítimo de mercancías en régimen de conocimiento de embarque no está afectado por competencias exclusivas ni por fueros especiales de protección y que, por tanto, habrá que atender a la sumisión expresa o tácita, al domicilio del demandado en territorio español y, finalmente, a los fueros especiales. Al tratarse de un tribunal de un Estado no miembro de la UE, la Audiencia aplica el sistema competencial de la LOPJ, lo que, traducido a nuestro estudio, supondría aplicar los arts. 4 a 8, 25 y 26 del Reglamento 1215/2012. 


\section{b) Supuestos especiales de protección}

72. Superadas las competencias exclusivas, encontramos los supuestos especiales de protección que son: seguros (arts. 10 a 16), contratos celebrados por consumidores (arts. 17 y 19) y contratos individuales de trabajo (arts. 20 a 23 ).

73. En el primer caso, estamos ante un contrato entre el tomador del seguro y su aseguradora; en el segundo, ante un contrato celebrado por un consumidor para un uso que pueda considerarse ajeno a su actividad profesional; y en el tercero, ante una relación laboral entre el empleado y su empleador. Se puede comprobar mediante una lectura de los correspondientes artículos que el transporte objeto de estudio no es un contrato de seguro, un contrato celebrado por un consumidor ni un contrato de individual de trabajo ${ }^{96}$. Se trata, como hemos visto ya, de una relación mercantil entre empresarios que actúan en el marco de su actividad.

74. Quiere esto decir que, al no ser una materia afectada por una competencia exclusiva ni por un supuesto especial de protección ${ }^{97}$, se permite la sumisión expresa de acuerdo con los requisitos formales del art. 25.1 del Reglamento 1215/2012, como ha señalado nuestra jurisprudencia patria ${ }^{98}$, desplazando el fuero general del domicilio del demandado y los fueros especiales por razón de la materia ${ }^{99}$.

\section{c) Sumisión tácita como criterio de atribución de competencia}

75. En un proceso que tenga por objeto una demanda fundada en un contrato de transporte marítimo internacional de mercancías en régimen de conocimiento de embarque, la comparecencia del demandado, como en cualquier otro proceso declarativo de Derecho sustantivo, para realizar cualquier gestión que no sea la de proponer en forma la declinatoria, así como la proposición extemporánea de la

${ }^{96}$ En caso de poder encajar en algún supuesto especial de protección, nuestro objeto de estudio podría encajar en los contratos celebrados por consumidores. En este sentido, es importante señalar que ninguna de las partes intervinientes en estos contratos de transporte puede ser considerada consumidor o usuario en el sentido que estas figuras son definidas por su legislación específica, a la cual nos remitimos.

${ }^{97}$ Consideramos que son dos las resoluciones de referencia que, combinadas, son clave a la hora de concretar la normativa aplicable y de determinar la competencia judicial internacional. En primer lugar, el Auto de 11 de octubre de 2006 del Juzgado de lo Mercantil núm. 4 de Barcelona, FFJJ. 4 y 5. En segundo lugar, por su utilidad práctica y sencillez en sus argumentos, la SAP de Pontevedra núm. 676/2006, de 21 de diciembre, FJ. 3. El Auto nos indicaba la jerarquía normativa a la hora de determinar la competencia judicial internacional en supuestos como los que estudiamos en el presente trabajo y nos resolvía el primer problema: la jerarquía normativa y, por consiguiente, nos indicaba la norma aplicable. Por su parte, la Sentencia que señalamos ahora, nos resuelve el segundo problema: la admisibilidad o no de prórroga de competencia en el transporte marítimo internacional. Realizando un sucinto pero completo análisis del sistema competencial del Reglamento, la Audiencia aplica dicho sistema a un transporte marítimo internacional de mercancías descartando competencias exclusivas, supuestos especiales de protección y sumisión tácita (en ese caso concreto). La Audiencia concluye que resulta de aplicación el fuero especial ratione materiae del art.5.1, letra b) del Reglamento 44/2001, ante la ausencia de una cláusula de atribución de competencia y por el hecho de que la demandada estaba domiciliada en Francia y se le demanda en España, donde se entregan las mercancías. Aunque el supuesto concreto sometido a la Audiencia consistía en un contrato de fletamento por viaje, en puridad se trataba de un transporte marítimo internacional de mercancías, solo que, bajo otra modalidad, por lo que podemos aplicar el análisis que efectúa esta sentencia a la modalidad de transporte marítimo de mercancías que nos ocupa en este trabajo.

${ }_{98}$ Entre las resoluciones que recurren a este argumento para aplicar el Reglamento 1215/2012 podemos citar las siguientes: SSAP de Barcelona, de 20 de diciembre de 1999, FJ. 8; de Valencia núm. 220/2000, de 18 de octubre, FJ. 4; de Pontevedra núm. 160/2000, de 8 de mayo, FJ. 2 y núm. 676/2006, de 21 de diciembre, FJ. 3; y AA de la AP de Madrid núm. 46/2004, de 22 de marzo, FJ. 4; de Barcelona núm. 252/2005, de 19 de octubre, FJ. 2 y núm. 101/2007, de 16 de abril, FJ. 4; y de Pontevedra núm. 30/2008, de 14 de febrero, FJ. 3; y el Auto núm.78/2015, de 4 de marzo, del Juzgado de lo Mercantil núm. 1 de Barcelona, FJ. 2; que está en la línea seguida por la jurisprudencia que lo precede y que debemos tener en cuenta aunque esté en primera instancia. Otras resoluciones en esta línea son los Autos núm. 117/2000, de 9 de junio, de la AP de Cantabria; núm. 27/2009, de 21 de enero, núm. 118/2009, de 19 de junio y núm. 428/2009, de 11 de marzo de 2010, de la AP de Barcelona; y núm. 143/2009, de 21 de julio, núm. 60/2010, de 23 de abril y núm. 140/2014, de 19 de septiembre, de la AP de Madrid, así como las Sentencias de 30 de julio de 2002, Rec. 2086/2002, y núm. 676/2006, de 21 de diciembre, de la AP de Pontevedra. También resulta interesante en este sentido, el considerando (19) del Reglamento 1215/2012.

${ }_{99}$ SSTJCE Segoura (As. 25/75), apdo. 5; Portaleasing (As. 784/79), apdo. 5; Estasis Salotti (As. 24/76), apdo. 7; y Tilly Russ (As. 71/93), apdo. 14; entre otras muchas. 
misma, supondrán su sumisión tácita (art. 56.1 ${ }^{\circ}$ LEC). En sector que nosotros estamos considerando, dicho demandado suele ser el porteador, contra el que se interpone demanda en España por el destinatario de las mercancías o su aseguradora, cuando se le produjo un daño o perjuicio derivado del transporte marítimo de las mercancías en cuestión.

76. Mientras que Cordero Álvarez define la sumisión tácita como un límite propio a la autonomía jurisdiccional de las partes ${ }^{100}$, otro sector doctrinal, como Guzmán Zapater / Herranz BaLlesteros, y Fontestad Portalés, la define como un criterio de atribución de competencia que opera con posterioridad a la sumisión expresa y que la deja sin efecto ${ }^{101}$. En esencia el resultado es el mismo en ambos casos. Lo explicamos de la siguiente manera: dado un acuerdo de atribución de competencia formalmente válido y plenamente eficaz, si el destinatario de las mercancías interpone demanda contra el porteador en España (art. 56.1 ${ }^{\circ} \mathrm{LEC}$ ) y éste contesta a la demanda o no impugna mediante declinatoria en tiempo y forma la competencia judicial internacional, incurrirá en sumisión tácita (art. 26.1 Reglamento 1215/2012) determinando así la competencia de los tribunales españoles (arts. 22.1 bis LOPJ y $\left.56.2^{\circ} \mathrm{LEC}\right)^{102}$. Ello se debe a que la sumisión tácita prevalece sobre la expresa ${ }^{103}$ y procede aunque exista un acuerdo atributivo de competencia, es decir, la sumisión tácita es un fuero de competencia tanto en el Reglamento 1215/2012 como en la LOPJ y en la LEC, sin perjuicio de las competencias exclusivas ${ }^{104}$.

77. En cualquier caso, no pretendemos en este trabajo hacer un estudio sistemático y profundo de la sumisión tácita, sino poner de relieve que, aun habiendo una cláusula de atribución de competencia inserta en un conocimiento de embarque formalmente válida, la sumisión tácita posterior del porteador implica la ineficacia de dicha cláusula ${ }^{105}$ y que así lo ha venido considerando la jurisprudencia.

78. Por esta razón, al no estar afectado el transporte marítimo de mercancías ni por una competencia exclusiva ni por un supuesto especial de protección, cuya sumisión tácita presenta algunas peculiaridades, la única manera de desvirtuar la eficacia de la cláusula de atribución de competencia desde el punto de vista del sistema competencial del Reglamento, es intentar que el porteador se someta tácitamente a los tribunales españoles ${ }^{106}$.

\section{d) Límite general a la autonomía jurisdiccional de las partes}

79. Al estudiar el ámbito material de aplicación del Reglamento 1215/2012 para analizar si el transporte marítimo internacional de mercancías en régimen de conocimiento de embarque era subsumi-

100 C. I. Cordero Álvarez, “Análisis metodológico...”, cit., apdo. I, letra b).

${ }^{101}$ M. Herranz Ballesteros / M. Guzmán Zapater, "La competencia judicial internacional en el Reglamento (CE) núm. 44/2001 (I): ámbito de aplicación, foros objetivos y atribución de la competencia judicial internacional por voluntad de las partes", p. 20 [Consultado en 04/01/2019]. Acceso en: http://www5.poderjudicial.es/CVcm/Temas4-6/Tema\%204/Tema_4_ ES.pdf; y L. Fontestad Portalés, El transporte..., cit., p. 503.

${ }_{102}$ Téngase en cuenta al estudiar la sumisión tácita que, dado el momento en que fueron dictadas algunas de las resoluciones citadas, el actual art. 56 de la Ley 1/2000, que regula la sumisión tácita, era el art. 58 de la LEC de 1881. En cualquier caso, el contenido de ambos artículos es esencialmente el mismo.

${ }^{103}$ Sobre esta idea y sus consecuencias procesales, vid. Wolters KLUwEr. "Sumisión procesal”. [Consultado el 04/01/2019]. Acceso en: http:/guiasjuridicas.wolterskluwer.es/Content/Documento.aspx?params=H4sIAAAAAAAEAE2OQUsDQQyFf425CLK2FXqZy9oeClLELuI1Oxt3gtOkzmTW7r93dD0YCPngvTzeZ6E0d3Q1dypnznxTmuZ9LbeXpJ4yRsizqMxn16VCYNhn1wB6Kxh36hfmiTrsK2saKLVzJVPD-ELZPawgB_064sQjGqu0mJYsHga3f2t-5n6z2m5hopSrwb3ySGIEKD5ococ1BB7DU11bPjNh8uEZR3IHYc96h_lyhSgftdLpV_xvbItZje1NFg18rHeHRo8YSYa_Qt8NuMtSCgEAAA==WKE.

${ }^{104}$ AAP de Pontevedra núm. 81/2001, de 19 de mayo, FJ. 5; a propósito de sumisión tácita de un porteador.

${ }^{105}$ C. I. Cordero Álvarez, “Análisis metodológico...”, cit., apdo. III.

${ }^{106}$ Hemos encontrado varias resoluciones en las que, existiendo una cláusula de atribución de competencia inserta en un conocimiento de embarque que en principio resultaría formalmente válida y eficaz, el porteador ha realizado alguna actuación procesal que ha supuesto su sumisión tácita a los tribunales españoles. Se trata, en cualquier caso, de un número minoritario de resoluciones, pero que deben tenerse en cuenta, pues suponen la diferencia entre litigar en España o donde señale la cláusula. Dichas resoluciones son las siguientes: SSAP de Barcelona, de 17 de octubre de 1994; de 29 de diciembre de 1999; de 12 de mayo de 2000; y núm. 397/2004, de 15 de septiembre; de Valencia núm. 260/2001, de 4 de mayo; y núm. 21/2006, de 25 de enero; y de Pontevedra núm. 335/2003, de 12 de mayo; y AAP de Vizcaya núm. 774/2000, de 26 de septiembre, y de Cádiz núm. 232/2000, de 3 de octubre. 
ble en dicho Reglamento, decíamos que no había límites materiales y que jurisdiccionalmente, solo hay un límite general a la autonomía jurisdiccional de las partes.

80. Dicho límite ha sido puesto de manifiesto por EsPINAR VICENTE ${ }^{107}$, cuando habla de las variantes que puede adoptar la sumisión expresa, y por nosotros, cuando afirmamos que la derogatio fori del tribunal en principio competente implica necesariamente la prorrogatio fori de otro tribunal. Lo anterior quiere decir que la derogación de la competencia de un tribunal se configura como un efecto no autónomo, pues sin prorrogar la competencia de otros tribunales no se puede alterar el juego de los demás foros del Reglamento ${ }^{108}$. Dicho de otra manera, sin designar tal alternativa, ello supondría dejar al supuesto de hecho litigioso "huérfano" de jurisdicción, lo que evidentemente no resulta admisible ni se ha apreciado en las sentencias y autos estudiados ${ }^{109}$.

81. En definitiva, este es el único límite que hemos apreciado, aunque sea desde un punto de vista meramente teórico, y que resulta aplicable a la autonomía jurisdiccional de las partes, no solo en acuerdos de atribución de competencia insertos en conocimientos de embarque, sino en cualquier clase de acuerdo de atribución de competencia. Sin embargo, es de señalar que ningún porteador que desee la plena eficacia y validez formal de un acuerdo de atribución de competencia, va a realizar una derogatio fori $i$ in su correspondiente prorrogatio fori y así se puede constatar en los autos y sentencias estudiadas ${ }^{110}$.

\section{Vinculación entre el tribunal designado y la relación jurídica litigiosa}

82. En ocasiones se cuestiona la validez y eficacia de la cláusula de atribución de competencia sobre la base de que el tribunal designado en la cláusula y el contrato de transporte marítimo no presentan ningún vínculo. Este planteamiento es totalmente lógico y razonable ${ }^{111}$ y es que, el hecho de que el contrato de transporte no presente vínculos con el tribunal del Estado designado en la cláusula de atribución de competencia, es un "argumento de cierta entidad"112.

107 J. Ma . Espinar Vicente, Tratado Elemental de Derecho Internacional Privado. Universidad de Alcalá, Alcalá de Henares, 2008, p. 308.

108 J. Ma . Espinar Vicente, Tratado..., cit., p. 308. En nuestro caso, a falta de acuerdo de atribución de competencia, entrarían en juego el fuero general del domicilio del demandado (arts. 4 a 6 Reglamento 1215/2012) y los fueros especiales ratione materiae (arts. 7 a 9 Reglamento 1215/2012). Por ello, si lo que se desea es que el proceso se celebre en un Estado miembro de la UE distinto de España, lo que procederá es un acuerdo de atribución de competencia en el que se designe la jurisdicción de ese otro Estado, derogando implícitamente la jurisdicción de los tribunales españoles competentes inicialmente en base a los mencionados foros generales y especiales.

${ }_{109}$ Cuando decimos que la derogatio fori sin su correlativa prorrogatio fori no resulta admisible, entendemos no que no sea posible (porque materialmente sí lo es), sino que directamente se tendría por no puesta la cláusula y entrarían en juego el fuero general del domicilio del demandado y los fueros especiales ratione materiae, a elección del actor.

${ }_{110}$ Precisamente se llega al recurso de apelación porque normalmente el destinatario de las mercancías o su aseguradora, habiendo visto estimada la declinatoria del porteador tras haberle demandado en España, sigue discrepando de la prorrogatio fori del tribunal del Estado miembro de la UE designado en la cláusula de atribución de competencia, mientras que el porteador sigue defendiendo en segunda instancia su validez formal y oponibilidad. También puede ser que el porteador haya visto desestimada su declinatoria en primera instancia y se proponga en segunda lograr la estimación de aquélla. En cualquier caso, lo que se pretende poner de relieve es la voluntad del porteador de conseguir la eficacia de la cláusula de atribución de competencia.

${ }^{111}$ Creemos que fue totalmente legítimo plantear en su momento si la falta de vinculación "tribunal designado-relación jurídica litigiosa", podía afectar a la validez y eficacia de la cláusula de atribución de competencia, sobre todo en transportes marítimos internacionales en los que concurren partes de muy diversos lugares del mundo. Si se es experto en Derecho Marítimo y Procesal, el planteamiento de esta duda nos parece que constituía una buena estrategia procesal, más razonable y coherente que otros motivos que podrían alegarse. $\mathrm{Si}$, por el contrario, se es lego en la materia, la duda es más que razonable y comprensible cuando observamos que nos pueden llevar a litigar lejos de un fuero conocido y al que estamos habituados.

112 AAP de Madrid núm. 143/2009, de 21 de julio, FJ. 3. En esta resolución, la Audiencia reconoce una cierta relevancia al hecho de que el contrato de transporte (entrega de mercancías en España) y el Estado designado en la cláusula de atribución de competencia (Reino Unido), no presenten ningún vínculo. Seguidamente, y como se expondrá a lo largo del presente apartado, la jurisprudencia concluye que dicha ausencia de vínculo no es relevante a efectos de analizar la validez y eficacia de la cláusula de acuerdo con el Reglamento 1215/2012. 
83. En síntesis, lo expuesto ahora consiste en cuestionar la validez y eficacia de la cláusula de atribución de competencia, alegando que el tribunal designado no presenta ninguna relación con el objeto del litigio y/o con las partes del mismo. Podríamos, por tanto, plantear la ausencia de dicho punto de conexión como causa de ineficacia de la cláusula, alegando que el cumplimiento del contrato se realiza en España, que nuestra contraparte es una parte domiciliada en España, que la misma tiene sede en nuestro país, o que las mercancías fueron cargadas en España.

84. La respuesta a esta cuestión la encontramos tanto en la jurisprudencia del TJUE, como en nuestra jurisprudencia patria. La jurisprudencia del TJUE parte de la idea según la cual el art. 25 del Reglamento 1215/2012 hace abstracción de cualquier elemento de conexión entre la relación objeto del litigio y el Tribunal designado, por lo que la elección del tribunal sólo puede apreciarse en base a las exigencias que establece el art. 25 del Reglamento 1215/2012 ${ }^{113}$. Esto significa que el Reglamento hace prevalecer la voluntad de las partes sobre dichos elementos configurando una competencia exclusiva, salvo pacto en contra. Tampoco se puede realizar un examen adicional sobre la justificación de la cláusula ni del objetivo o finalidad buscada por la parte que la insertó ${ }^{114}$.

85. Precisamente porque se permite la designación de un tribunal independientemente de los puntos de conexión que existan con el mismo, se exige que la cláusula de atribución de competencia cumpla con alguno de los requisitos formales estrictos que establece el art. 25.1 del Reglamento 1215/2012 $2^{115}$, que tienen por finalidad garantizar la seguridad jurídica y asegurar el consentimiento de las partes. Además, vincular la validez y eficacia de estas cláusulas a la posible relación entre el tribunal designado y el objeto del litigio supondría exigir un requisito adicional para enjuiciar las citadas cláusulas, lo que no resulta admisible de acuerdo con el Reglamento 1215/2012 y con la jurisprudencia del TJUE ${ }^{116}$.

86. Por su parte, nuestra jurisprudencia patria, siguiendo los argumentos señalados en el párrafo anterior, realiza una serie de precisiones que debemos destacar. En primer lugar, señala que la falta de conexión con el tribunal designado no es motivo suficiente para cuestionar la atribución competencial (AAP de Madrid núm. 180/2012, de 21 de diciembre, FJ. 6; y núm. 34/2015, de 9 de febrero, FJ. 4) ${ }^{117}$. Tenemos que matizar que, no es que dicho motivo no sea suficiente para impugnar la validez y eficacia de la cláusula de atribución de competencia, es que directamente no es admisible como motivo ${ }^{118}$. En segundo lugar, señala que nuestros tribunales no pueden examinar ninguna clase de vínculo personal y/o material entre el tribunal designado y la relación jurídica litigiosa (SAP de Pontevedra núm. 13/2002, de 14 de enero, FJ. 5).

87. En resumen, no se puede cuestionar la validez y eficacia de una cláusula de atribución de competencia inserta en un conocimiento de embarque por el mero hecho de que ni las partes ni el objeto del litigio presenten vínculos de ningún tipo, ya sean personales, materiales o geográficos, con el tribunal designado por estas cláusulas, pues no lo exige ni el Reglamento 1215/2012 ni su jurisprudencia interpretativa.

${ }^{113}$ Esta abstracción se ha mantenido invariable desde el Convenio de Bruselas de 1968 y sus modificaciones, hasta el actual Reglamento 1215/2012. En este sentido se pueden consultar las SSTJCE Zelger (C-56/79), apdo. 3; Benincasa (C-269/95), apdo. 28; MSG (C-106/95), apdo. 34; y Castelletti (C-159/97), apdos. 49 a 52.

114 STJCE Castelletti (C-159/97), apdo. 51.

115 STJCE MSG (C-106/95), apdo. 34.

${ }^{116}$ Los Estados miembros de la UE no están facultados para establecer requisitos adicionales de ningún tipo, más allá de lo que establece el art. 25.1 del Reglamento 1215/2012.

117 Otras resoluciones que presentan idéntica o similar argumentación son los Autos núm. 287/2001, de 10 de septiembre y núm. 131/2003, de 22 de diciembre, de la AP de Cádiz; núm. 2/2006, de 13 de enero y núm. 159/2011, de 20 de octubre, de la AP de Las Palmas; y núm. 143/2009, de 21 de julio, núm. 5/2012, de 16 de enero, núm. 180/2012, de 21 de diciembre y núm. 140/2014, de 19 de septiembre, de la AP de Madrid; así como las SS núm. 13/2002, de 14 de enero, de la AP de Pontevedra; núm. 38/2006, de 6 de febrero, de la AP de Valencia; y núm. 20/2016, de 19 de septiembre, de la AP de Pontevedra.

${ }^{118} \mathrm{La}$ AP de Madrid lo que hace es argumentar de una manera diplomática la imposibilidad de alegar dicho motivo, pero podría haber dicho directamente que no resulta admisible como motivo de recurso, por no estar contemplada la exigencia dicho vínculo por el Reglamento 1215/2012. 


\section{Aplicabilidad proyectada del art. 468 LENMAR}

88. Teniendo claro el tipo de transporte en el que surgen estas cláusulas y la norma de referencia a nivel europeo, el paso final es analizar el Derecho nacional aplicable en nuestro caso o, lo que es lo mismo, la Ley de Navegación Marítima. El Capítulo Primero del Título IX de la Ley de Navegación Marítima $^{119}$ contiene las llamadas especialidades de jurisdicción y competencia. Dos son los artículos que la Ley dedica a esas especialidades ${ }^{120}$, siendo el art. 468 el que más problemas de interpretación está planteando de cara al futuro de las cláusulas de jurisdicción. El problema en discusión no es otro que la oponibilidad a terceros de las citadas cláusulas ${ }^{121}$, que trataremos más adelante al hilo de la aplicabilidad futura del mencionado artículo. Con este propósito, tenemos que realizar una lectura conjunta del art. 468 LENMAR con el art. 251 del mismo texto.

89. Debido a que la LENMAR fue promulgada el 14 de julio de 2014, publicada en el BOE el 25 de julio y en vigor desde el 25 de septiembre de ese mismo año, han visto la luz pocas resoluciones aplicando e interpretando ${ }^{122}$ un artículo tan problemático en la práctica como interesante desde el punto de vista doctrinal ${ }^{123}$.

90. En esta parte final vamos tratar de proyectar en el futuro la aplicación del art. 468 LENMAR, atendiendo a las diferentes posiciones doctrinales sobre el mismo hasta el momento presente, la mayoría a su favor en España, y teniendo siempre en cuenta que solo los pronunciamientos judiciales futuros resolverán definitivamente la cuestión ${ }^{124}$.

\section{Planteamiento general del problema}

91. Los arts. 251 y 468 LENMAR son dos artículos cuya razón de ser y problemática debe ser tratada mediante una lectura conjunta de ambos preceptos. El art. 251 LENMAR $^{125}$, regulador de la eficacia traslativa del conocimiento de embarque, dispone que la transmisión del mismo:

119 BOE núm. 180, de 25 de julio de 2014, pp. 59193 a 59311. Referencia: BOE-A-20147877.

${ }^{120}$ El art. 469 LENMAR, regulador de los criterios de atribución de competencia, es el segundo precepto de las especialidades procesales que operará cuando las partes no hayan introducido válidamente una cláusula de atribución de competencia, es decir, cuando hayamos aplicado el art. 468. Así, se establece que serán competentes, a elección del actor, los tribunales del domicilio del demandado, los del lugar de celebración del contrato o los del puerto de carga o descarga. Para Del CorTe, estos preceptos constituyen una solución especial distinta del régimen general de la LOPJ. En este sentido vid. J. DeL CoRTE, "Especialidades procesales en la Ley de Navegación Marítima", en A. Emparanza Sobejano / J. M. Martín Osante (Dirs.), Comentarios sobre la Ley de navegación marítima, Marcial Pons, Madrid, 2016, p. 754.

${ }^{121}$ Dado que la oponibilidad a terceros no es un tema que vaya a ser tratado en profundidad en el presente estudio, nos remitimos a V. Fuentes CAmacho / R. SAnz Abascal, “¿Puede afectar una cláusula de sumisión a una aseguradora que alega no haberla suscrito?, Diario La Ley, N 6390, 2005; y T. Fernández Quirós, "Oponibilidad frente a terceros de las cláusulas de jurisdicción en los conocimientos de embarque”, en VV. AA., Comentarios a la Ley de Navegación Marítima, Dykinson, Madrid, 2015, pp. 429-440.

${ }^{122}$ Nos referimos a sentencias y autos de Audiencias Provinciales y del Tribunal Supremo.

${ }^{123} \mathrm{La}$ AP de Valencia realiza unas valiosas consideraciones que nos permiten entender mejor la problemática y tratamiento que podría recibir esta cuestión: “(...) el examen de la cuestión relativa a la eficacia (...) de una (...) cláusula de sumisión (...) y la eventual extensión de sus efectos (...) debe realizarse (...) para cada supuesto fáctico (...) en que se ha de proceder a la constatación de los diversos aspectos que permitan obtener la conclusión más ajustada a derecho. No siempre (...) la inclusión de la cláusula (...) puede tener por efecto la derogación de la jurisdicción de los Tribunales españoles (...). No cabe desconocer (...) la polémica actual y pareceres contradictorios en torno al alcance y efectos de los artículos 468 y 469 de la [LNM] en relación con el art. 251 (...) que resulta de diversos trabajos doctrinales (...)" (AAP de Valencia núm. 1243/2016, de 27 de julio, FJ. 4; núm. 1244/2016, de 27 de julio, FJ. 4; y núm. 615/2017, de 15 de mayo, FJ. 3). Coincidimos plenamente con dicha Audiencia en que el análisis de la validez y eficacia de una cláusula de jurisdicción debe hacerse caso a caso y en función de la valoración de sus concretas circunstancias, siempre, eso sí, aplicando la normativa adecuada al supuesto.

${ }^{124}$ Un excelente repaso de las sentencias más destacadas del Tribunal Supremo hasta el año 2009 puede consultarse en P. Martorell Zulueta, "La Jurisprudencia española sobre las cláusulas de sumisión en el tráfico marítimo a la luz del derecho comunitario europeo", Anuario de Derecho Marítimo, nº. 26, 2009, pp. 157-183. En este trabajo la magistrada analiza y explica las resoluciones más relevantes sobre la materia, que han sido dictadas tanto en cláusulas jurisdiccionales como en cláusulas arbitrales.

${ }^{125}$ Sobre este artículo de la LENMAR, vid. I. Arroyo Martínez, "Artículo 251. Eficacia traslativa”, en I. Arroyo MartíneZ / J. A. Rueda Martínez (Coords.), Comentarios a la Ley 14/2014, de 24 de julio de navegación marítima, Civitas, Madrid, 2016, pp. 841 y 842 . 
"producirá los mismos efectos que la entrega de las mercancías (...). El adquiriente (...) adquirirá todos los derechos y acciones del transmitente sobre las mercancías, excepción hecha de los acuerdos en materia de jurisdicción (...), que requerirán el consentimiento del adquiriente en los términos señalados en el capítulo I del título $I X^{\prime \prime 26}$

92. Se consagra así la eficacia traslativa del conocimiento de embarque, salvo por lo que respecta a las cláusulas de jurisdicción, cuyo consentimiento, según la LENMAR, debe expresarse en la forma que prescribe el Capítulo I del Título IX de dicha Ley. Esta eficacia traslativa del conocimiento de embarque contrasta con la que regulaba el art. 708 del ya derogado Libro III del Código de Comercio y que disponía que "aquel a quien se trasfiera el conocimiento adquirirá sobre las mercaderías expresadas en él todos los derechos y acciones del cedente o del endosante".

93. Podemos concluir de la lectura del art. 251 LENMAR que el adquiriente del conocimiento de embarque sucederá al cargador en todos sus derechos y acciones de forma automática, pero para suceder en la cláusula de jurisdicción habrá que atender a lo dispuesto en el otro artículo que comentamos seguidamente.

94. El art. 468 LENMAR, precepto que podría ser considerado de carácter proteccionista y calificable de vuelta al imperialismo jurisdiccional ${ }^{127}$, dispone que:

"Sin perjuicio de lo previsto en los convenios internacionales vigentes en España y en las normas de la Unión Europea, serán nulas y se tendrán por no puestas las cláusulas de sumisión a una jurisdicción extranjera o a arbitraje en el extranjero, contenidas en los contratos de utilización del buque o en los contratos auxiliares de la navegación, cuando no hayan sido negociadas separadas e individualmente.

En particular, la inserción de una cláusula (...) en el condicionado impreso de cualquiera de los contratos (...) no evidenciará, por sí sola, el cumplimiento de los requisitos exigidos (...)”.

95. La redacción de dicho artículo plantea problemas interpretativos de importantes consecuencias en la práctica y ha dividido a la doctrina entre quienes consideran que resulta aplicable y quienes no. De esto nos ocupamos en los siguientes apartados.

\section{Sobre la posible aplicabilidad del art. 468 LENMAR}

96. Entre quienes se han aventurado a afirmar la posible aplicabilidad y alcance del art. 468 LENMAR, se encuentra GABALDÓN GARCIAA ${ }^{128}$. Para este autor el precepto citado podría suponer la invalidez de las cláusulas de jurisdicción insertas en conocimientos de embarque cuando aquéllas designen órganos judiciales situados fuera de la UE o de la EFTA y no hayan sido negociadas separada e individualmente. Prosigue el autor señalando que el mismo razonamiento puede realizarse cuando se designe un tribunal de la UE o de la EFTA, pues la LENMAR lo que ha hecho es aprovechar las posibilidades que ofrecía la STJCE Coreck ${ }^{129}$. Hay que indicar que GABALDÓN GARCíA no da por hecho la aplicabilidad del art. 468 LENMAR, sino que, a la luz de la lectura de dicho artículo, plantea la posible aplicabilidad del mismo y se remite a las futuras resoluciones judiciales que se dicten en la materia. Consideramos, por tanto, que es una posición prudente y coherente con la dicción del precepto.

${ }^{126}$ Para FeRnández Rozas la redacción de este precepto "no parece excesivamente feliz (...), puesto que el hecho de que las cláusulas de sumisión no negociadas separadamente se consideren inválidas bajo los criterios del ordenamiento jurídico español, no implica que dichas cláusulas sean inválidas conforme al ordenamiento jurídico del Estado a cuyos tribunales hacen remisión, lo cual no impediría que este tercer Estado se declare eventualmente competente". Para un mayor desarrollo, vid., J. C. Fernández Rozas, "Alternativas e incertidumbres de las cláusulas de solución de controversias en la contratación marítima internacional", Cuadernos de Derecho Transnacional, no 2, 2018, p. 362.

${ }^{127}$ Para una lectura completa de esta idea vid. J. Ma . AlCÁNTARA, “¿De nuevo, el «nacionalismo» marítimo español?”, Derecho de los Negocios, $\mathbf{n}^{\mathbf{0}} \mathbf{2 2 3}, \mathbf{2 0 0 9}, \mathbf{p .} \mathbf{2 3}$.

128 J. L. Gabaldón García, Compendio de Derecho Marítimo español, Marcial Pons, Madrid, 2016, p. 256.

${ }^{129}$ STJCE de 9 de noviembre de 2000, As. C-387/98, Coreck Maritime GmbH c. Handelsveem BV y otros. 
97. El argumento de este autor es la base sobre la que la doctrina y los profesionales del sector en España están argumentando que debido a la LENMAR se ha puesto fin al automatismo con el que venían admitiéndose estas cláusulas. No le falta razón a esta posición doctrinal, pues es verdad que la STJCE Coreck ${ }^{130}$ pareció dejar abierta esta vía al señalar que:

"en la medida que la cláusula atributiva de competencia es válida (...) en la relación entre el cargador y el porteador, dicha cláusula puede ser invocada frente al tercero, tenedor del conocimiento, desde el momento en que, con arreglo al Derecho nacional aplicable, el tenedor (...) se subroga en los derechos y obligaciones del cargador"131.

98. También con base en el argumento del autor comentado, SÁncheZ-Horneros AdÁN ${ }^{132}$ va un paso más allá y afirma contundentemente que los tribunales españoles que enjuicien la cláusula de jurisdicción deberán partir de lo establecido en el art. 468 LENMAR. En segundo lugar, considera que las sentencias del Tribunal Supremo posteriores a la ratificación del Convenio de Bruselas de 1968, no podrán servir de base a nuestros juzgados a la hora de afirmar la efectiva existencia del uso consistente en incluir estas cláusulas.

99. La conclusión, de acuerdo con esta posición doctrinal, es que el art. 468 LENMAR en relación con el art. $251^{133}$, aprovechando el margen reconocido al Derecho nacional aplicable por la STJCE Coreck, habría eliminado la posibilidad de que el tercero tenedor del conocimiento de embarque quede sujeto por una cláusula de jurisdicción sobre la que no ha prestado su consentimiento individual y separado del resto de cláusulas. En este sentido se pronuncia el Auto núm. 218/2016, de 21 de diciembre, de la Audiencia Provincial de Barcelona. En el presente caso, la Audiencia aplica el art. 468 LENMAR, en relación con el art. 251 de la misma norma, para desestimar en apelación la declinatoria del porteador al entender que la LENMAR ha acogido la posibilidad que venía dada por la jurisprudencia comunitaria o, en palabras de la Audiencia, “(...) la nueva LNM modifica el régimen de oponibilidad de las cláusulas de sumisión a lo terceros que no son parte en el contrato (el destinatario que recibe el conocimiento de embarque del cargador y los sucesivos tenedores) (... $)^{134}$. Entendemos que la eficacia traslativa del conocimiento de embarque ha de realizarse con arreglo (...) al artículo 251 LNM (...)". Así, considera la Audiencia que la cláusula de jurisdicción no es extensible al tercero tenedor del conocimiento de embarque. Consideramos que se trata de una resolución más que cuestionable, pues obvia tanto el art. 25 Reglamento 1215/1012 como su jurisprudencia interpretativa de referencia (especialmente las SSTJUE Coreck Maritime, Tilly Russ y Castelletti), así como nuestra mejor doctrina procesalista y mercantilista. Contrariamente a esta posición, aunque de instancia, encontramos el Auto núm. 295/2016, de 13 de septiembre, del Juzgado de lo Mercantil $n^{\circ} 6$ de Madrid $^{135}$. Dicha resolución estima la declinatoria del

${ }^{130}$ Para un análisis en profundidad de la citada resolución, vid. H. AguILAR Grieder, "Cláusula de elección de foro, conocimiento de embarque y artículo 17 del Convenio de Bruselas de 27 de septiembre de 1968. (1)", Diario La Ley, núm. 9, 2000, pp. 1402-1410.

131 STJCE Coreck, apdos. 23 a 27. En esta sentencia se citan otras dos importantes resoluciones del TJUE: Tilly Russ adpo. 24 y Castelletti adpo. 41.

${ }_{132}$ A. Ma . SÁnchez-Horneros AdÁn, "La Ley 14/2014, de 24 de julio, de navegación marítima: última llamada para la jurisdicción española en asuntos marítimos", Diario La Ley, núm. 8802, 2016, pp.10 y 11. Al margen de que no podemos compartir este razonamiento, por las razones que se expondrán al hablar de la inaplicabilidad del art. 468 LENMAR, la autora denuncia una situación de desigualdad contractual inter partes que es, sin duda, un problema frecuente en estos contratos y que compartimos plenamente.

${ }^{133}$ Sobre las posibilidades que ofrece el art. 251 LENMAR, en función de si resultase aplicable o no, vid. J. Del CoRTE, "Especialidades...”, en A. Emparanza Sobejano / J. M. Martín Osante (Dirs.), Comentarios ..., cit., pp. 766-768.

${ }^{134}$ En este sentido, vid. I. Arroyo, "La protección de la parte débil frente a las cláusulas de jurisdicción internacional en el transporte marítimo", Anuario de Derecho Marítimo, no 20, 2013, pp. 25 y ss. Para este autor, la validez de las cláusulas objeto de estudio ha sufrido un importante cambio con los nuevos requisitos que establece el art. 468 LENMAR.

135 Otras resoluciones actuales en este sentido han sido ya tratadas por J. C. FERNÁndEZ RozAs, “Alternativas...”, cit., pp. 364 y 365. En ellas, prevalece el art. 25 del Reglamento 1215/2012, desplazando al art. 468 LENMAR, y se mantiene la oponibilidad a terceros de las cláusulas de jurisdicción (AAP de Pontevedra, núm. 523/2017, de 16 de octubre). También se cita un Auto del Juzgado de lo Mercantil n ${ }^{\circ} 6$ de Madrid, en el que no vamos a entrar aquí por ser de instancia, aunque apunta la línea jurisprudencial que podría seguirse en el futuro. 
porteador y la considera válida basándose en los Autos núm. 143/2009, de 21 de julio y núm. 60/2010, de 23 de abril de 2010, de la Audiencia Provincial de Madrid, así como extensible al tercero en base a la STJUE Refcomp (C-543/10), con acertados argumentos. Nótese que la Audiencia Provincial de Barcelona basa su fundamentación en función del sujeto que acciona contra el porteador. Así las cosas, si quien acciona es el cargador, haya o no firmado el conocimiento de embarque, considera la Audiencia que aplica el Reglamento 1215/2012 sin lugar a dudas. Tenemos que decir que este argumento es del todo lógico y no aporta gran novedad, pues en este caso no existe ningún tercero a quien oponer la cláusula de prórroga de jurisdicción: la relación jurídica será exclusivamente entre cargador y porteador. Por otro lado, cuando quien acciona es el destinatario de las mercancías o los sucesivos tenedores del conocimiento, entonces considera la Audiencia que sí resulta aplicable el art. 468 LENMAR en relación con el art. 251 de la misma norma. Argumentación, todo sea dicho, que no podemos compartir por las razones que se explican más adelante al hablar de la no aplicabilidad de la LENMAR ${ }^{136}$.

\section{Sobre la posible inaplicabilidad del art. 468 LENMAR}

100. A continuación se exponen tres argumentos por los cuales podemos afirmar que el art. 468 LENMAR no resultaría aplicable a las cláusulas de jurisdicción insertas en conocimientos de embarque cuando el tribunal designado se encuentre en cualquier Estado miembro de la UE. Para una mejor comprensión se ha separado la razón esencial en tres apartados. Dicha razón esencial radicaría en la primacía del Derecho de la UE y, consecuentemente, en la imposibilidad de los Estados miembros de establecer requisitos adicionales a los previstos por la normativa comunitaria, a lo que hay que añadir la circunstancia de ir en contra de la práctica habitual del sector ${ }^{137}$.

\section{A) Primacía del Derecho Internacional General y del Derecho de la Unión Europea}

101. La afirmación de que el art. 468 LENMAR no resultaría aplicable derivaría de su propia dicción cuando señala que las cláusulas serán nulas si no han sido negociadas separadas e individualmente, "sin perjuicio de lo previsto en los convenios internacionales vigentes en España y de las normas de la Unión Europea". Esto nos lleva directamente a realizar una breve reflexión sobre las fuentes del Derecho Marítimo y a una lectura conjunta del art. 468 LENMAR con el art. 2 de la misma ley. En efecto, ambos artículos consagran la primacía del Derecho Internacional General y del Derecho de la Unión Europea y, además, el art. 2 LENMAR señala que dicha norma se aplicará en tanto no se oponga a lo dispuesto por los tratados internacionales vigentes en España y en las normas de la Unión Europea y que, en todo caso, para la interpretación de las normas contenidas en dicha Ley se atenderá a la regulación contenida en los tratados internacionales vigentes en España y la conveniencia de promover la uniformidad en la regulación de las materias objeto de la misma.

102. De esta lectura conjunta podemos extraer la conclusión de que la primera fuente del Derecho Marítimo ${ }^{138}$ son los tratados internacionales vigentes en España y las normas de la UE, así como que la LENMAR será aplicada cuando no se oponga al Derecho Internacional y de la Unión Europea,

${ }^{136}$ Otra cuestión diferente sería si, por ejemplo, el transporte no llega a realizarse por resolución de mutuo acuerdo inter partes por prestación defectuosa de un servicio anexo o complementario al mismo. En este sentido, no procede invocar los términos y condiciones generales (entre ellos la cláusula de atribución de competencia) de un transporte que no llegó a realizarse por haberlo decidido así las partes, como con gran acierto señala la AP de Valencia en su Auto núm. 1885/2016, de 28 de diciembre, FJ. 3.

${ }^{137}$ Sobre esta última idea el Consejo de Estado señaló que, en relación con el art. 468, “(...) valora positivamente la intencionalidad y finalidad de la norma proyectada, pero no puede dejar de llamar la atención sobre el hecho de que se opone frontalmente a la práctica habitual y generalizada seguida en el tráfico y que previsiblemente tendrá una eficacia muy dudosa". Para la consulta del Dictamen, vid. BOE. Dictámenes del Consejo de Estado, Procedencia Justicia, núm. de expediente 449/2013, de 24 de julio de 2013.

138 J. L. Gabaldón García, Compendio..., cit., pp. 19-21. Para un estudio en profundidad de las fuentes del Derecho se pueden consultar, entre otros muchos, I. Arroyo Martínez, "Artículo 2. Fuentes e interpretación”, en I. Arroyo Martínez / J. A. Rueda Martínez (Coords.), Comentarios..., cit., pp. 83- 86; A. B. Campuzano / E. Sanjuán, "El Derecho Marítimo en España. La Ley de Navegación Marítima”, en A. B. Campuzano / E. Sanjuán (Dirs.), Comentarios ...cit., pp. 36- 38; y J. L. Pulido Begines, Curso..., cit., pp. 36- 40. 
así como que su interpretación se hará conforme a dichas normas supranacionales con la finalidad de uniformizar la regulación de las materias tratadas. Por tanto, desde la perspectiva de la primacía del Derecho de la UE, no parece posible afirmar la aplicación de la LENMAR cuando la cláusula designe un tribunal sito en cualquier Estado miembro de la UE, por la primacía del Reglamento 1215/2012 sobre la LENMAR, recudiendo el ámbito de aplicación de ésta ${ }^{139}$.

\section{B) Interpretación alternativa de la STJCE Coreck en relación con la primacía del Derecho de la UE}

103. Quien suscribe estas líneas considera posible otra interpretación de la STJCE Coreck, diferente de la que se ha realizado hasta ahora. En este sentido, si bien es verdad que la STJCE Coreck pareció dejar abierta la posibilidad de limitar la eficacia de las cláusulas atributivas de competencia vía Derecho nacional aplicable, esto resulta discutible si entendemos que dicha posibilidad implica la facultad de los Estados miembros de establecer requisitos adicionales a los que establece el art. 25 del Reglamento 1215/2012.

104. La sentencia señalaba que la cláusula de jurisdicción inserta en un conocimiento de embarque será oponible frente al tercero tenedor del conocimiento si éste había sucedido al cargador de acuerdo con el Derecho nacional aplicable. De esto se deducía, aplicando el art. 708 del derogado Código de Comercio, que la cláusula era oponible a dicho tercero y, en su caso, a su aseguradora de acuerdo con el art. 43 de la Ley de Contrato de Seguro ${ }^{140}$. Habiendo sucesión, por tanto, resultaba indiferente que el tercero hubiese prestado o no su consentimiento para quedar vinculado por la cláusula ${ }^{141}$. En la actualidad el problema surge porque la LENMAR dispone en su art. 251 que el tercero sucede al cargador en todos sus derechos y acciones, pero no en lo relativo a las cláusulas de jurisdicción que, remitiéndose al art. 468 de la misma Ley, deben ser negociadas separadas e individualmente.

105. Aun considerando aplicable el art. 468 LENMAR en relación con el art. 251, entendiendo que la sentencia deja ese margen al Derecho nacional aplicable, la STJCE Coreck señala que si el tercero tenedor no ha sucedido de acuerdo con el Derecho nacional aplicable, como sucede en la LENMAR, se deberá analizar su consentimiento, pero no a la luz de dicho Derecho interno sino de acuerdo con la norma comunitaria (ahora el art. 25.1 Reglamento 1215/2012) ) $^{142}$. Esto significa que si aplicamos el art. 251 LENMAR y consideramos que el tercero tenedor no ha sucedido al cargador por lo que respecta a la cláusula de jurisdicción, deberemos analizar dicho consentimiento a la luz del art. 25.1. c) Reglamento $1215 / 2012$ y no en base al art. 468 LENMAR $^{143}$.

139 Sobre la idea de eficacia limitada del art. 468 LENMAR, vid. M. GómEz JENÉ, "Las cláusulas de jurisdicción y arbitraje en la nueva Ley de Navegación Marítima", Cuadernos de Derecho Transnacional, n 2, 2014, p. 115; A. Zurimendi Isla, "El contrato de fletamento: documentación”, en A. EMParanza Sobejano / J. M. Martín OsanTe, (Dirs.), Comentarios..., cit., p. 372; y J. M. GonzÁlez Pellicer, "Sobre el artículo 468 del Proyecto de Ley de Navegación Marítima y la nulidad de las cláusulas de elección de foro en los conocimientos de embarque", Diario La Ley, núm. 8354. 2014, apdo. II.4.b).

${ }^{140}$ BOE núm. 250, de 17 de octubre de 1980. Referencia BOE-A-1980-22501.

${ }^{141}$ H. Aguilar Grieder, "Cláusula de elección..." cit., apdo. VI.

142 STJCE Coreck apdo. 26.

${ }^{143}$ Queremos dejar indicados unos interesantes casos de oponibililidad a una aseguradora por parte de un transitario que actuaba como porteador contractual (Auto núm. 324/2017, de 16 de octubre, de la AP de Pontevedra), papel que también podría asumir un consignatario de buques y, en consecuencia, ampararse en la cláusula de jurisdicción. En la resolución ahora citada, la transitaria asumió el transporte de una mercancía frente al comprador/cargador y para ello contrató con una naviera-porteadora efectiva. Verificado un problema de descongelación, la aseguradora subrogada en la posición del cargador acciona contra la transitaria y ésta opone la cláusula de jurisdicción inserta en el conocimiento de embarque de la naviera. En primer lugar, la Audiencia señala que el Reglamento 1215/2012 desplaza a la LENMAR. En segundo lugar, señala que la responsabilidad exigida por la aseguradora se basa en la equiparación de responsabilidad que el art. 278 LENMAR hace entre el transitario y el porteador efectivo, disponiendo que "si lo que se exige al transitario es la responsabilidad solidaria que la ley le impone con quien realiza personalmente el trasporte por su propios medios (...) y si este último contrata, de manera conocida (...) con cláusulas de jurisdicción, resulta lógico entender que las condiciones contractuales del transportista resultan también aplicables a quien por ley es su garante solidario, frente a quien encargó el transporte". En un caso similar, aunque con distintas partes, podemos citar la Sentencia núm. 20/2016, de 19 de enero, de la misma Audiencia. En dicho caso, la aseguradora basó 
106. Todo ello se justificaría por la imposibilidad de los Estados miembros de establecer requisitos adicionales a los que establece el Reglamento comunitario ${ }^{144}$, lo que, en cierto sentido, parece hacer el art. 468 LENMAR al exigir una negociación individual y separada que el Reglamento no exige para ningún tipo de cláusula atributiva de competencia esté o no inserta en un conocimiento de embarque. Por tanto, lo que parecería más razonable a afectos de comprobar el consentimiento del tercero tenedor del conocimiento, sería realizar una lectura del art. 25.1.c) Reglamento 1215/2012 y analizar si nos encontramos con un sujeto que actúa en el comercio internacional y que conoce o debiera conocer la inserción de las cláusulas atributivas de competencia como uso ampliamente conocido y observado por las partes en dicho sector ${ }^{145}$.

107. Por último, consideramos interesante traer a colación dos de las posiciones más críticas sobre los arts. 251 y 468 LENMAR que han sido mantenidas por ZURIMENDI IsLA ${ }^{146}$ y por IRACULIS ARREGUI. Para el primer autor, el art. 468 LENMAR constituye una excepción de dudoso fundamento al régimen comunitario e internacional y se aplicará, como hemos dicho ya nosotros, si no es de aplicación un Tratado internacional o legislación comunitaria. Señala que la interpretación que pretende dar prioridad a los mencionados artículos, aun cuando se deba aplicar la normativa y jurisprudencia comunitarias, resulta carente de base legal y técnica. Dicha interpretación, según el autor, respondería a los indisimulados intereses de la abogacía española y de las aseguradoras de nuestro país y es insostenible en un país como España que apoya el libre comercio, la economía de mercando y está integrado en el mercado único europeo.

108. Continúa señalando que, si el fuero elegido tiene un punto de conexión real con el caso o con la situación empresarial del porteador y que la elección de dicho fuero se debe al objetivo de centralizar todas las reclamaciones que los clientes puedan hacer reduciendo así los costes de gestión, entonces no se aplicarían los artículos mencionados, pues no habría abuso en la elección del fuero. Solo cuando falte esta explicación económico-lógica puede aparecer el ánimo de obstaculizar o impedir las reclamaciones, lo que motivaría el abuso y la aplicación del art. 468 LENMAR $^{147}$. En la línea con lo

su acción en la equiparación de responsabilidad que hacía el art. 379 del Código de Comercio, asemejable en esencia al art. 278 LENMAR, y dispuso que la aseguradora "demanda al transitario por entender que debe responder de los daños (...) al haberse encargado (...) del transporte (...) y ser (...) la que asumió los riesgos". Por ello, la aseguradora no puede "impedir al transitario de su derecho a valerse de las cláusulas previstas en ese mismo conocimiento de embarque, que le resultan extensibles no solo para lo que interesa (...), sino en su conjunto (...)”. Finalmente, aplicando los arts. 247 del Código de Comercio y 1.148 del Código Civil, llegó a la misma solución el Auto núm. 1620/2016, de 8 de noviembre, de la AP de Valencia, FJ. 4. En este caso, sin embargo, es el cargador quien acciona directamente contra la transitaria, quien actuó en calidad de intermediario contratando el transporte en nombre del cargador-comitente, produciendo efectos entre comitente y naviera.

${ }^{144} \mathrm{Al}$ ser una norma de Derecho derivado, vinculante, típica, obligatoria en todos sus elementos y directamente aplicable en todos los Estados miembros de la UE (arts. 288 del TFUE y 81 del Reglamento 1215/2012), los Estados miembros no pueden reducir, aumentar o matizar las exigencias para la validez de las cláusulas de atribución de competencia cuando resulte aplicable el Reglamento. En este sentido se pronuncia nuestro Alto Tribunal, entre otras, en las SS. núm. 697/2005, de 29 de septiembre de 2005, FJ. 1; y núm. 428/2008, de 27 de mayo, FJ. 2, con cita de importante doctrina del TJUE. Esto se relaciona también con la idea antes apuntada de la primacía del Derecho de la UE.

${ }^{145}$ Sobre la prestación del consentimiento del tercero tenedor del conocimiento de embarque cuando el Derecho nacional aplicable considera que aquél no sucedió al cargador en sus derechos y acciones, vid. E. Torralba Mendiola, "Las especialidades procesales en la Ley de navegación marítima: cláusulas de jurisdicción y arbitraje", Revista de derecho del transporte: Terrestre, marítimo, aéreo y multimodal, $\mathrm{N}^{\circ} .16,2015$, p. 127. La autora señala la idea de que la falta de sucesión del tercero exigirá la verificación de su consentimiento en los términos previstos en el Reglamento 1215/2012. Por lo que respecta a la jurisprudencia, el Auto núm. 1243/2016, de 27 de julio, de la AP de Valencia, FJ. 4 parece hacer esta consideración, cuando considera que no quedó probado que ambas partes confirmaran la cláusula de jurisdicción y tampoco considera probado que el demandante operase habitualmente en el sector y debiera conocer el uso de incluir dichas cláusulas. Añade, además, que entre las comunicaciones inter partes, no resulta referencia alguna a la cláusula de jurisdicción. Se deduciría de lo ahora expuesto que la oponibilidad de la cláusula a terceros descansa sobre la fundamentación probatoria de que dicho tercero conoce el uso comercial consistente en incluir dichas cláusulas, así como que se hizo mención expresa de la cláusula en algún momento de la relación contractual y que así se hizo constar en algún documento contractual.

${ }^{146}$ Para una lectura desarrollada, vid. A. ZuRIMENDI IsLA, "Las cláusulas de jurisdicción y arbitraje incluidas en el conocimiento de embarque tras la Ley de Navegación Marítima", Revista de derecho del transporte: Terrestre, marítimo, aéreo y multimodal, $\mathrm{N}^{\circ} .18,2016$, pp. 89-110.

147 No compartimos plenamente este argumento, aun partiendo de que es una consideración del todo acertada con la dicción 
ahora comentado, IRACULIS ARREGUI afirma que el art. 468 presenta un formalismo excesivo y, por tanto, criticable al entender que desvirtúa los requisitos formales establecidos por la normativa europea ${ }^{148}$.

\section{C) Conclusiones del Encuentro de los Magistrados de los Mercantil 2016 (especial mención al art. 468 LENMAR)}

109. Un último argumento a favor de la inaplicabilidad del art. 468 LENMAR, que vendría a resumir lo dicho hasta ahora, lo encontramos en las Conclusiones del Encuentro de Magistrados de lo Mercantil $2016^{149}$, que emitieron a propósito del artículo objeto de discusión, además de otras cuestiones que no son objeto del presente trabajo. Los magistrados de lo mercantil realizaron una labor interpretativa del art. 468 LENMAR reflejando las siguientes conclusiones ${ }^{150}: 1^{\text {a }}$. Si la cláusula se refiere a un tribunal español, no se aplicará el art. $468 \mathrm{LENMAR}^{151} ; 2^{\mathrm{a}}$. Si la cláusula se refiere a un tribunal sito en cualquier Estado miembro de la UE, se aplicará el Reglamento 1215/2012 ${ }^{152}$; y 3 ${ }^{\mathrm{a}}$. Solo cuando la cláusula se refiera a un tercer Estado resultará aplicable el control del art. 468 LENMAR $^{153}$.

\section{Conclusiones}

110. A pesar de lo todo lo expuesto en la última parte del presente trabajo, al art. 468 LENMAR sigue generando dudas sobre su aplicabilidad real. Como hemos apuntado en el trabajo solo los pronunciamientos judiciales futuros de nuestras Audiencias Provinciales y, sobre todo, de nuestro Tribunal Supremo vendrán a aclarar una cuestión tan controvertida y problemática en la práctica. Pero quizá, quien venga a resolver la cuestión sea el TJUE.

111. Nos referimos a la posibilidad de que en un proceso que se desarrolle en España en el que se discuta la validez de una cláusula de jurisdicción inserta en un conocimiento de embarque en el que se

del precepto. Nuestra discrepancia surge del hecho ya apuntado de que nuestros tribunales no pueden entran a juzgar la razón por la que la parte correspondiente incluyó la cláusula de atribución de competencia. Tanto si lo hizo por desincentivar las posibles reclamaciones como si lo hizo para centrarlas todas en un fuero concreto, lo que importa en puridad es el cumplimiento de los estrictos requisitos del art. 25 del Reglamento 1215/2012, que no exigen entrar en el análisis de ninguna de las razones por las cuales se incluyó la cláusula en el conocimiento de embarque.

${ }_{148}$ Para una lectura desarrollada, vid. N. IRACUlis ArRegUi, "La controvertida negociación individual y separada de las cláusulas de jurisdicción y arbitraje en la Ley de Navegación Marítima”, Revista de derecho del transporte: Terrestre, marítimo, aéreo y multimodal, $\mathrm{N}^{\circ}$. 18, 2017, pp. 173-208.

${ }^{149}$ Conclusiones del Encuentro de Magistrados de lo Mercantil 2016. [Consultado el 04/01/2019]. Acceso en https:// www.fidefundacion.es/attachment/764936/. Un desarrollo doctrinal muy clarificador de estas conclusiones lo encontramos en M. Chacón Cadenas, “Artículo 468. Cláusulas de jurisdicción y arbitraje”, en I. Arroyo Martínez / J. A. Rueda Martínez (Coords.), Comentarios..., cit. pp. 1401-1404.

${ }^{150}$ Conclusiones sustancialmente similares las podemos extraer de E. SANJú́n, “Especialidades...”, en A. B. Campuzano / E. SAnjuÁn (Dirs.), Comentarios..., cit., pp. 487 y 488.

${ }^{151}$ Una crítica a esta distinción entre lo nacional y lo extranjero ha sido expresada con precisión por ARIZA COLMENAREJO cuando señala que "[El art. 468 LENMAR] se refiere a órganos jurisdiccionales (...) situados fuera del territorio nacional. (...) Parece ser la intención del legislador discriminar jurisdicción nacional (...) frente a extranjera". Para la lectura completa de la explicación, vid. Ma . J. ArizA ColmenAREJo, "Cláusulas de jurisdicción y arbitraje en la Ley de Navegación Marítima de 2014", Anuario de Derecho Marítimo, no. 32, 2015, pp. 120-128. También en este sentido, vid. A. BADIA, "Capítulo XXIX. Jurisdicción y competencia", en VV. AA., Comentarios ..., cit., p. 427. Este autor señala, en la referencia ahora citada, que la distinción entre lo extranjero y lo nacional puede tener "dificil encaje en el Tratado de la UE y en los Acuerdos de la Organización Mundial del Comercio, cuyos principios rectores se asientan en la no discriminación por razón de nacionalidad, la libertad de contratación y la eliminación de barreras y obstáculos comerciales".

${ }^{152}$ Las conclusiones $2^{\mathrm{a}}$ y $3^{\mathrm{a}}$ encajan con lo dicho en el presente trabajo sobre la primacía del Derecho de la UE.

${ }^{153}$ La tercera conclusión de los magistrados ha sido sustancialmente desarrollada en J. DeL CoRTE, "Especialidades...”, en A. Emparanza Sobejano / J. M. Martín Osante (Dirs.), Comentarios... cit., pp. 762, 763, 765 y 766 . Por su parte, la jurisprudencia señala en un caso de sumisión a un tribunal no comunitario que "no mediando cláusula sumisoria a Tribunales de un Estado de la [UE], ni es estando atribuida exclusivamente la competencia a los Juzgados de Hong Kong (...), procede la aplicación al caso de las normas nacionales (...). No siendo de aplicación el Reglamento 1215/2012, se ha de estar al régimen legal que resulta de los artículos 468 y 469 de la Ley de Navegación Marítima (...). El examen de la cláusula (...) no supera (...) los requisitos de incorporación [de los] artículos 5 y 7 b) de la Ley 7/1998 de 13 de abril (...)” (AAP de Valencia núm. 615/2017, de 15 de mayo, FJ. 3). 
solicite la aplicación del art. 468 LENMAR en relación con el art. 251 de la misma Ley, el juez español plantee una cuestión prejudicial al TJUE del siguiente tenor:

a) ¿Es contrario al art. 25.1 del Reglamento 1215/2012 la exigencia por parte del Derecho nacional aplicable de negociación individual y separada de una cláusula de jurisdicción inserta en un conocimiento de embarque que se remite a un tribunal de la UE?

b) ¿Supondría dicha exigencia de negociación individual y separada la exigencia de requisitos adicionales no permitidos por el Reglamento ni por la jurisprudencia del TJUE?

c) ¿Respetaría esta exigencia la posibilidad abierta por la STJCE Coreck?

112. Más que nunca parecen necesarios nuevos pronunciamientos del TJUE, como lo hizo en ocasiones anteriores con las Sentencias Castelletti y Coreck, así como pronunciamientos de nuestro Alto Tribunal. Por ello consideramos que el planteamiento en este sentido de cuestiones prejudiciales por parte de nuestros jueces y magistrados ayudaría a esclarecer definitivamente la cuestión.

113. En virtud de todo lo expuesto en este trabajo, podemos realizar unas apreciaciones finales sobre la LENMAR y los artículos controvertidos objeto de estudio:

a) Si entendemos que el art. 468 LENMAR es contrario y cede ante lo dispuesto en el art. 25 Reglamento 1215/2012, entonces tampoco resultaría aplicable el art. 251 LENMAR. De esta forma, el régimen de las cláusulas de jurisdicción insertas en conocimientos de embarque y su oponibilidad no habría cambiado para las cláusulas referidas a tribunales de la Unión Europea.

b) Si, por el contrario, entendemos que lo que hacen los arts. 251 y 468 LENMAR es aprovechar el margen abierto por la jurisprudencia comunitaria, entonces el régimen de las citadas cláusulas y su oponibilidad habría visto su fin en España tal y como lo conocíamos hasta la entrada en vigor de la LENMAR.

114. A modo de cierre del presente estudio y realizadas las consideraciones oportunas sobre los artículos controvertidos de la LENMAR, no podíamos dejar de mencionar un aspecto importantísimo de esta cuestión, quizá el más importante, que es la relación entre la salida del Reino Unido de la UE y las cláusulas de atribución de competencia. Como se puede apreciar de las resoluciones estudiadas y, en general de cualquier resolución que analicemos sobre la cuestión objeto de estudio, la prevalencia del Reino Unido en cuestiones marítimas es palmaria.

115. Dos consecuencias se siguen de esta salida. En primer lugar, y sin perjuicio de los acuerdos a que se lleguen en los meses por venir, el Reino Unido pasaría a ser considerado un tercer Estado y, por tanto, no le sería de aplicación el Reglamento 1215/2012 y en el caso del Convenio de Lugano de 2007, le será de aplicación con las particularidades señaladas. Consecuentemente, los cargadores, destinatarios de mercancías o sus aseguradoras, podrán impugnar la validez y eficacia de las cláusulas de jurisdicción insertas en conocimientos de embarque como si designasen tribunales de Tokyo, Nueva York o Shanghai, es decir, como un Estado extracomunitario.

116. Por otra parte, los porteadores que quieran seguir viendo estimadas sus declinatorias en base a la normativa europea, casi de forma automática, deberán cambiar la designación de sus cláusulas para referirse a tribunales de Estados miembros de la UE. Aún resulta precipitado sacar conclusiones sobre la cuestión del Reino Unido, aun así, de las resoluciones estudiadas podemos deducir que quizá se produzca un desplazamiento de las designaciones a la High Court of Justice of London hacia Estados como Francia (tribunales de Le Havre, Marsella y París), los Países Bajos (tribunales de Ámsterdam y Rotterdam) o Alemania (tribunales de Hamburgo), o quizá se intente también potenciar el arbitraje comercial internacional.

117. Finalmente no queda más que indicar que el presente estudio refleja las conclusiones extraídas por el autor en base al análisis efectuado de la normativa y la jurisprudencia citada en el mismo y no deben ser entendidas como una opinión en nombre de Cepsa. 